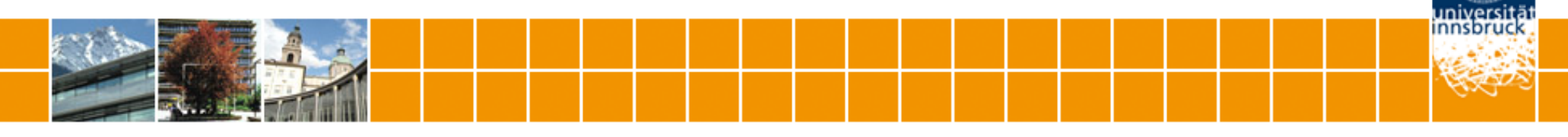

\title{
Role selection and team performance
}

David J. Cooper, Matthias Sutter

Working Papers in Economics and Statistics

2011-14

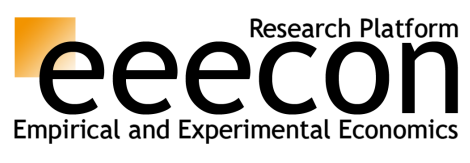

University of Innsbruck

http://eeecon.uibk.ac.at/ 


\title{
Role selection and team performance*
}

\author{
David J. Cooper ${ }^{\#}$
}

Florida State University

\section{Matthias Sutter ${ }^{\dagger}$ \\ University of Innsbruck and University of Gothenburg}

\begin{abstract}
Team success relies on assigning team members to the right tasks. We use controlled experiments to study how roles are assigned within teams and how this affects team performance. Subjects play the takeover game in pairs consisting of a buyer and a seller. Understanding optimal play is very demanding for buyers and trivial for sellers. Teams perform better when roles are assigned endogenously or teammates are allowed to chat about their decisions, but the interaction effect between endogenous role assignment and chat unexpectedly worsens team performance. We argue that ego depletion provides a likely explanation for this surprising result.
\end{abstract}

JEL-Code: C91, C92

Keywords: Role selection in teams, team performance, takeover game, winner's curse, communication, experiment

This version: 26 July 2011

\footnotetext{
* We would like to thank Hal Arkes, Rachel Croson, Guillaume Frechette, John Kagel, Peter Kriss, Scott Tindale and seminar participants at Florida State, SJDM, EWEBE and the ASSA meetings for helpful comments. We thank Björn Brand, Krista Jabs and Roland Jansky for assistance in programming and running the experiments, Glenn Dutcher for help with preparing the text, and Richard Krenndorfer and Alessandor de Spirito for coding the dialogues. Special thanks to Mark DeVault for teaching us about recent advances in software development. Financial support from the University of Innsbruck and the NSF (SES - 0924772) is gratefully acknowledged.

\# Department of Economics, Florida State University, Tallahassee, FL 32306-2180, USA. e-mail: djcooper@fsu.edu

${ }^{\dagger}$ Department of Public Finance, University of Innsbruck, Universitaetsstrasse 15, A-6020 Innsbruck, Austria. email: matthias.sutter@uibk.ac.at
} 


\section{Introduction}

Motivated by the observation that many important economic decisions are made by teams rather than individuals, experimental economics has recently witnessed a surge of interest in team decision making. Extending the existing psychology literature to domains of specific interest to economists, researchers have established that team choices are generally more rational (e.g. Cooper and Kagel, 2005; Blinder and Morgan, 2005; Kocher and Sutter, 2005; Charness and Jackson, 2007) and more self-interested than individuals (e.g. Bornstein and Yaniv, 1998; Luhan, Kocher, and Sutter, 2009). These studies have focused on comparing teams with individuals and have generally not emphasized the internal organization of teams. A universal feature of existing studies is that team members are all engaged in the same task. While appropriate for establishing basic observations about how teams perform relative to individuals, use of homogenous tasks departs significantly from the reality of many team environments. Team members in most environments are filling different roles and completing different tasks. Not all team members are equally well suited for all tasks, so getting the right person assigned to the right task can be an important determinant of team success. In this paper we examine role assignment and team performance in a team task where one role requires considerably more strategic thought than the other, making proper role assignment crucial for the success of a team.

It is by no means trivial to correctly assign people to tasks, both because it may not be obvious who is best suited for each task and because team members may desire tasks for which they are poorly suited. Professional sports provide many good examples of this. For instance, typically different people are in charge of signing players for a team (the general manager or GM) and coaching the team. Both jobs are critical for the success of the team and there isn't an obvious hierarchical relationship between the two jobs. ${ }^{1}$ Many coaches want to control the teams' personnel decisions, either by formally taking on the title of GM or by performing the GM's duties while having a subordinate hold the title. This can harm the team's performance since the skills that make a good coach aren't the same as the skills that make a good GM. For example, Mike Holmgren was a successful coach in American football, leading Green Bay to a championship by winning the Super Bowl following the 1996 season. Holmgren left Green Bay in 1999 to take over in Seattle as both coach and GM. This was unsuccessful and Holmgren was fired as the GM (but not as coach) in 2002. Acting solely as a coach, Holmgren led Seattle to the Super Bowl following the 2005 season. Team success

\footnotetext{
${ }^{1}$ In most teams, the GM is theoretically the coach's boss with the right to hire and fire. In practice the positions are fairly equal with decisions on hiring and firing for both jobs made higher in the organizational hierarchy by a team owner or president.
} 
relied on Holmgren being placed in the role he was best suited for, but it took failure and direct intervention by the team's upper management to get him assigned to the correct role.

Turning to a field that is less glamorous (but probably more important economically) than professional sports, software development provides an interesting mixture of different ways that tasks might be assigned. Large software projects usually require a development team. The traditional way of running a software development team is to have an externally assigned project manager. Team members do not choose their tasks, but are instead assigned tasks by the project manager. Over the past decade, software development has moved towards "agile software development", a broad category that encompasses a number of specific software design approaches such as Scrum, Extreme Programming, and Crystal Clear. The shift toward agile software development involved many changes in the design process, including a move toward teams that are self-managed. As an example consider Scrum, one of the most popular variants of agile software development. Teams using Scrum meet on a regular basis to set short-term goals. No specific team member is designated as the team leader. Tasks are assigned via discussion among the team members, with the idea that team members know more about each other and the tasks to be performed than any outside individual.

Even in a field like software development that offers a broad variety of methods for assigning individuals to tasks, using field data to study the relative effectiveness of methods is problematic. $^{2}$ Agile software development involves a multitude of changes to traditional methods of software development, and any two implementations differ on multiple dimensions. Even if there existed sufficient variation that the effect of different elements of the process could be identified via multivariate regressions, there would remain the problem of endogeneity. It is not random what software development process is adopted by a particular firm and no obvious instrument exists for the process adoption decision.

We therefore turn to laboratory experiments to study the role of task assignment in determining team effectiveness. Using lab experiments lets us choose a task where role assignment is critical. In a lab experiment we can control crucial elements of the environment such as incentives, information available to team members, and (most importantly) the process by which roles are assigned, and makes it possible to observe all the interactions among team mates. The latter point is important since we want to understand the process that leads to certain rules for task assignment being more effective.

\footnotetext{
${ }^{2}$ See Chow and Cao (2008) for a study of the effectiveness of agile software development.
} 
Going into the details of the experimental design, subjects play a simplified version of the takeover game (Samuelson and Bazerman, 1985). The takeover game is played by two individuals, a Buyer and a Seller. The Seller has a single item to sell. She knows the value of this item while the Buyer only knows the distribution of values. The value of the item to the Buyer is always $150 \%$ of the value to the Seller. The Buyer submits a bid to buy the item. If the Seller accepts the bid, the Seller's payoff is the difference between the bid and her value while the Buyer's payoff is the difference between his value and his bid. If the Seller rejects the bid, both the Buyer and Seller get a payoff of zero. The Seller's payoff maximizing strategy is trivial: she should accept any bid greater than her value. Because of the asymmetric information between Buyers and Sellers, the Buyer faces adverse selection. In choosing a bid he needs to understand that the expected value of the item conditional on having his bid accepted is less than the expected value ex ante. The adverse selection is sufficiently severe that submitting a bid equal to the lowest possible value is the Buyer's payoff maximizing strategy.

Previous work on the takeover game has focused on why the winner's curse (overbidding) occurs, but our intent is to use the takeover game to understand how task assignment affects team performance. For our purposes, two features of the takeover game are particularly valuable. First, the Buyer and Seller roles differ greatly in difficulty. The Seller's optimal strategy is trivial, but previous work (e.g., Grosskopf, Bereby-Meyer and Bazerman, 2007; Bereby-Meyer and Grosskopf, 2008; Charness and Levin, 2009) has established that Buyers have a great deal of difficulty understanding that they need to bid low due to adverse selection. Buyers consistently overbid even when the problem is highly simplified and played repeatedly. Second, play by freely interacting teams reduces but does not eliminate overbidding in the takeover game (Casari, Zhang, and Jackson, 2010). This allows us to study the relationship between the importance of role selection and the degree of interaction between teammates. ${ }^{3}$

In the initial phase of the experiment, all subjects play as Buyers facing a series of computerized Sellers. In control sessions the Buyers continue to play against computerized Sellers for the second phase of the experiment. For the other four treatments in our experimental design, subjects are matched into teams of two players each. One teammate plays exclusively as a Buyer and the other plays exclusively as a Seller. Each plays a series of takeover games against Buyers and Sellers from other teams and split their earnings evenly.

\footnotetext{
${ }^{3}$ In Casari et al. (2010) groups consist of three members who are all in the role of buyers (while sellers were computerized). Unlike the work we present below, their paper does not focus on role selection and how it affects team performance.
} 
Teammates never play against each other, so their interests are perfectly aligned. The four treatments with teams systematically vary along two dimensions: (1) the Buyer and Seller roles are either assigned randomly and exogenously or are endogenously agreed upon by the two teammates, and (2) teammates either play independently, only interacting through their shared payoffs, or are given periodic opportunities to chat about how to play the game. $E x$ ante, we expect either endogenous role selection or chat between teammates to improve the Buyers' performance by lowering bids. ${ }^{4}$ When the two are combined, with teammates discussing both what roles to take and how to play the game, we hypothesize that their performance will improve more (bids will be lower) than with chat or endogenous role assignment alone since teams can get the more able individual assigned to the Buyer role as well as taking advantage of insights from the teammate assigned to the Seller role. ${ }^{5}$

We find that chat with random role assignment leads to significantly lower bids compared to the baseline treatment of random role assignment and no interactions between teammates. Endogenous role assignment without chat also causes a significant reduction in bids compared to the baseline. To our surprise, bids are higher with chat and endogenous role assignment than with either chat or endogenous role assignment alone and are no longer significantly lower than in the baseline. The combination of chat and endogenous role assignment harms performance rather than improving it.

Underlying our hypotheses about treatment effects were a pair of behavioral assumptions: (1) chat between teammates improves a Buyer's performance controlling for ability and (2) endogenous role assignment will improve the sorting of high ability individuals into the Buyer role. In the treatment with chat and endogenous role assignment, neither of these assumptions is supported by the data. Controlling for Buyer ability, chat significantly reduces bids when role assignment is random but has virtually no effect when role assignment is endogenous. The differing effects of chat are driven by differences in the dialogues between teammates; teams are significantly less likely to discuss either bidding or the benefits of bidding low when there is endogenous role assignment and chat rather than chat only. Combining chat and endogenous role assignment also harms the ability of teams to assign the right person to the right role. The process for selecting roles should favor individuals who bid low in the initial stage for the role of Buyer. Buyers indeed bid significantly less than their

\footnotetext{
${ }^{4}$ The Seller's role is sufficiently trivial that we expected subjects to get it right regardless of treatment. The data supports this expectation.

${ }^{5}$ If teammates were able to perfectly communicate their insights about playing as a Buyer, it wouldn't matter which individual became the Buyer. However, our data analysis finds that bids in the second phase are lower if the teammate who bid lower in the first phase is selected as Buyer. This effect is lessened but not eliminated when teammates can chat. Not all teammates are willing or able to share their insights, so it matters which teammate becomes the Buyer.
} 
teammates assigned to the Seller role when there is only endogenous role assignment, but not when endogenous role assignment is combined with chat. This failure to consistently get the right person in the right role stems from the low quality of the underlying discussions. Teammates often fail to agree on role assignments, or don't abide by the agreements they have reached. They never cite performance in the initial phase as a justification for which teammate ought to be the Buyer. Allowing teams to discuss how to bid and who should take which role harms the performance of teams on both tasks.

We conjecture that the poor quality of discussion by teams with chat and endogenous role selection is due to the high demands this treatment makes on subjects' limited cognitive resources. Teammates do not face a significant time constraint when choosing roles and discussing how to bid, but have two separate tasks that require attention. Numerous psychology studies on ego depletion (e.g. Baumeister, Bratslavsky, Muraven, and Tice, 1998; Schmeichel, Vohs, and Baumeister, 2003) find that the strain multi-tasking places on subjects' cognitive budgets reduces performance on intellective tasks like choosing the best person for a role or understanding the benefits of bidding low.

Our results suggest some counter-intuitive advice for the assignment of tasks in teams. It is common wisdom that more employee involvement is better and that top-down management is counter-productive. While there is certainly some truth to these assertions (see Ichniowski and Shaw, 1999), traditional top-down management may not be entirely bad. When employees actively participate in choosing their roles, this increases the number of tasks that they need to perform. If there is interference between tasks, even when time constraints are not binding, exogenously assigning roles may free up employees' attention to focus on more critical tasks.

The paper is organized as follows. Sections 2 and 3 introduce the takeover game and the experimental design respectively. Section 4 develops initial hypotheses about likely treatment effects. Section 5 provides the results of the experiments, including analysis of the content of dialogues between teammates. Section 6 discusses the results.

\section{The Takeover Game}

Subjects in our experiment played a simplified version of the takeover game. This game involves two individuals, a Buyer and a Seller. The game begins with the Seller drawing a value, $\mathrm{V}$, for an indivisible item. This is the amount the item is worth to her. The possible values are 90, 600, and 1200 experimental points, with each value equally likely to be drawn. 
The Seller knows the value of the item while the Buyer only knows the distribution of values. The Buyer submits a bid, B, to purchase the item, where bids are restricted to the set of integers between 0 and 2000 (inclusive). The Seller observes the bid and chooses to either accept or reject it. If the bid is accepted, the Buyer's profit is $1.5^{*} \mathrm{~V}-\mathrm{B}$ and the Seller's profit is $\mathrm{B}-\mathrm{V}$. If the bid is rejected, both players' profits are zero.

The Seller's optimal strategy is simple - she should accept a bid if it is (weakly) greater than the value and reject otherwise. The Buyer's optimal bid is less obvious. If the Seller is behaving optimally, the Buyer's expected payoff maximizing bid is 90 . This is also the optimal bid for a risk averse buyer. In evaluating the profitability of a bid, the Buyer has to consider the expected value of the item subject to the bid being accepted. In other words, the Buyer must account for adverse selection. Table 1 illustrates the basic features of the Buyer's problem. A bid of 1200 induces all Sellers to accept the bid, including those with low (V = $90)$ and medium $(\mathrm{V}=600)$ values. Because the expected value of an item is only 630 points, even after a 50\% mark-up it isn't worth enough to make the bid profitable. The expected loss is large, 255 points, and Buyers lose money for two thirds of their bids.

\section{Table 1 about here}

A naïve reaction to the severe losses at a high bid is to bid something in the middle range, primarily to bid 600 . The Buyer now makes money if the item has medium value, but no longer gets to buy items with a high $(\mathrm{V}=1200)$ value. The expected value of an item subject to the bid being accepted is only 345 points. Even multiplying this by 1.5, the expected payoff of an accepted bid is -82.5 points. Unlike a high bid, feedback isn't going to make it obvious that a bid of 600 is a bad idea, because bids make money as often as they lose money and the expected loss isn't enormous. Learning to bid 90 is going to be difficult unless the Buyer recognizes the adverse selection problem and realizes that the only way to avoid losing money is to bid at the lowest possible value.

Our version of the takeover game borrows important features from Charness and Levin's (2009) "shifted" versions of the takeover game. The optimal bid of B = 90 earns the Buyer a small but steady profit. This avoids a problem with many versions of the takeover game where optimal play calls for earning no money and essentially taking no actions by never buying the item. Under these circumstances, action bias (Patt and Zeckhauser, 2000) becomes a plausible cause of overbidding that cannot be attributed to a failure to understand the expected payoffs of various bids. Setting a positive minimum value also means that the 
optimal bid isn't at the edge of the set of available bids. If pure errors play a role in bidding, it is possible to make an error that leads to underbidding as well as errors that lead to overbidding.

While any B > 90 is suboptimal, some errors are worse than others. Bids in the ranges B < $90,135 \leq \mathrm{B}<600,900 \leq \mathrm{B}<1200$, and $\mathrm{B} \geq 1800$ never earn a positive payoff if Sellers are behaving optimally. Given the constant negative outcomes for bids in these categories, we would expect even simple reinforcement learning to quickly eliminate them.

\section{Experimental Design}

Our experiment consisted of two parts. The first part, covering Rounds $1-10$, was identical in all treatments. The second part (Rounds 11 - 40) differed across treatments. The initial instructions for the experiment explained only Part 1, including three questions to check for understanding (see the appendix for a translation of the instructions). The Part 1 instructions told subjects that they would receive instructions for Part 2 after the conclusion of Part 1.

In Part 1, all subjects were in the role of Buyers. Sellers were computerized and always sold the indivisible item if the Buyer's bid was equal to or larger than the item's value in a given period. Each subject received starting capital of 12 Euros (3000 experimental points) for Part 1 from which possible losses could be covered. ${ }^{6}$ After each round, subjects got feedback about the item's value, whether they had bought the item or not, and how large their profit was.

In Part 2 we introduced five different treatments which are explained in the following.

1) Control. In this treatment, Rounds 11 - 40 were identical in structure to Rounds 1 10. Hence, all subjects remained in the role of Buyers, and Sellers were again computerized. This treatment serves as a benchmark for the possible effects of forming pairs of Buyers and Sellers in the following treatments. Buyers received an additional 10 Euros (2500 experimental points) of capital at the start of Part 2.

2) No Chat - Random. Here - and in the other treatments remaining to be introduced we randomly assigned pairs of subjects to be teammates at the beginning of Part 2. In the No Chat - Random treatment, one teammate was randomly assigned to the role of

\footnotetext{
${ }^{6}$ The 20 subjects who finished Part 1 with a negative balance, in spite of the starting capital, were allowed to continue to Part 2. These subjects were told that their Part 1 losses could be recouped in Part 2. Since all subjects received additional starting capital at the beginning of Part 2, only four Buyers started Part 2 with a net negative balance. If someone still had a loss after Part 2, it was not enforced. This was never mentioned in advance. There were 33 subjects $(5.6 \%)$ who ended the experiment in the red. The vast majority of these subjects (21 of 33) come from the Control treatment.
} 
Buyer in Rounds 11 - 40, and the other was assigned to the role of Seller. Subjects were informed about their roles before Round 11, and roles were fixed throughout Part 2. In this treatment and in the others to follow, a Buyer never played the takeover game against the Seller who was his teammate. This was common knowledge. Before Round 11 started, subjects in both roles were asked to enter some information about them that was then shown to their teammate. This information included age, gender, field of study, population of the hometown, working status, experience in experiments, grades in math and German from high school exit exams ("Maturanoten"). For a more detailed description of what data was gathered, see Table A.1 in the Appendix. In addition to this information, each member in the pair was informed about their teammate's total profit in Part 1. They were not shown the specific bids and values that led to the Part 1 profits. Other than this exchange of information, there was no opportunity for communication between the Buyer and the Seller in a team.

For Part 2, Buyers received 10 Euros (2500 experimental points) as additional starting capital, and Sellers received 2 Euros (500 experimental points). The total profits of a team's Buyer and Seller in Part 2, including the starting capital, were divided equally between the teammates at the end of Part 2 . This feature was stressed in the instructions for Part 2. Given the sharing of team profits, in practice each team received a joint additional endowment of 12 Euros (3000 experimental points) for Part 2. The feedback after each period in Part 2 was the same as in Part 1 for subjects in the role of Buyer. Sellers got as feedback the bid of the Buyer with whom they were paired in a given period (recall, this was never the Buyer from the Seller's team), the item's value, whether the Seller had sold the item, and the resulting profit. Subjects did not receive feedback about their teammates' outcomes.

3) Chat - Random. This treatment is identical to No Chat - Random, except that before Rounds 11, 21, and 31 the Buyer and the Seller in a team were allowed to chat with each other through an instant messaging program. Hence, although the roles within a team were again assigned randomly, Buyers and Sellers could exchange information and talk about the strategy they wanted to play. The chat was restricted to five minutes, which pilot sessions indicated was more than adequate time for a full discussion of the relevant issues. Subjects were free to say what they wanted in their communication, except that revealing their identity or using abusive language was forbidden. 
4) No Chat - Endogenous. This treatment differs from No Chat - Random only in the way the roles within each team were determined, but is identical in every other respect. After seeing the information (age, gender, etc.) about the other member of the team, one teammate was randomly drawn to make a proposal about the allocation of roles in the team. This proposal could be accompanied by a very short message of at most 100 characters. While the earnings from Part 1 provide a natural guide to which teammate should take which role, we gave subjects a number of other pieces of information about their teammate to avoid creating the impression that this specific piece of information had to be used in assigning roles. ${ }^{7}$ The other teammate could accept this proposal, and hence roles were determined accordingly, or propose roles to be assigned the other way round, again allowing for 100 characters to support the alternative proposal. If the original proposer accepted the alternative proposal, it was implemented. If not, roles were assigned randomly. Once determined, roles were fixed for Part 2.

5) Chat - Endogenous. This treatment is identical to Chat - Random, except that roles could be determined endogenously within each team. In the five minutes of chat before Round 11, subjects were instructed to consider the assignment of roles in their team, knowing that they were free to agree on either possible assignment of roles. When the chat was over, both teammates had to indicate in which role they wanted to be. If both teammates entered the same role, implying a conflict of interest, the role assignment was randomly determined. Otherwise, roles were assigned as requested by the teammates. Note that the assignment of roles could not be changed during the chats before Rounds 21 and 31 .

The experiment was run from November 2009 to April 2011 with a total of 592 participants, all of them students at the University of Innsbruck (which has a total of about 28,000 students). Recruitment was done using ORSEE (Greiner, 2004), and the sessions were computerized with zTree (Fischbacher, 2007) and run by the same experimenter (in order to avoid any kind of experimenter effects). We had 112 participants in treatment Control, and 120 in each of the other four treatments. No subject participated in more than one session. On average, an experimental session lasted 90 minutes, with those sessions where chat was possible lasting 15 minutes longer (due to the threefold opportunity to chat for 5 minutes).

\footnotetext{
${ }^{7}$ Several of these pieces of information could plausibly play a useful role in choosing a Buyer. For example, it seems natural that individuals with high test scores, particularly at math, might be good choices for the challenging role of a Buyer.
} 
Subjects were paid their cumulative earnings converted at a rate of 250 experimental points per Euro. The average earnings per subject were 17 Euros.

\section{Theory and Hypotheses}

The types of settings considered in the literature on team decision making can be roughly divided into "eureka" problems and judgment problems. ${ }^{8}$ A eureka problem is a problem that has a demonstrably correct solution. Ideally the solution should be difficult to reach without grasping a specific insight, but easily explained to another individual. Logic problems like the Wason selection task (Wason, 1966) are good examples of eureka problems. ${ }^{9}$ We argue that bidding optimally in the takeover game fits well into the framework of eureka problems. Given the results of previous studies on the winner's curse and the takeover game, we anticipate subjects will have difficulty learning to bid optimally. Since the feedback in favor of bidding lower rather than choosing intermediate bids (i.e., $\mathrm{B}=600$ ) is noisy, we think it unlikely that Buyers will learn to bid optimally in the absence of understanding the adverse selection problem they face. Obviously this won't be $100 \%$ true, as some Buyers will no doubt manage to bid optimally without understanding why they are doing so. The implication of this for our hypotheses is discussed below.

Define any bid in the range $90 \leq \mathrm{B}<135$ to be an "optimal bid". Bids in this range have positive expected value. Most of the optimal bids fall in the lower part of this range; $87 \%$ of the bids classified as optimal are either 90, 91, 95, or 100 points.

Thinking of the takeover game as a eureka type logic problem, we define a Buyer as having "solved the problem" if he bids optimally $(90 \leq \mathrm{B}<135)$. Let $\mathrm{p}(t, \pi)$ be the probability that an individual playing the takeover game solves the problem (bids optimally), where $t$ measures how long the individual has been trying to solve the problem (i.e., how many rounds of the takeover game have been played) and $\pi$ measures the expected payoff from solving the problem. We assume that $\mathrm{p}(t, \pi)$ is an increasing function of $t$ and $\pi$. Intuitively, we assume that individuals will learn to solve the problem over time and will expend more effort trying to solve the problem if the stakes are increased.

Comparing the Control and No Chat - Random treatments, any differences in bidding must occur because Buyers in the No Chat - Random treatment share their payoffs with a

\footnotetext{
${ }^{8}$ Judgment problems don't have a correct solution, but instead involve arriving at a group preference. Deciding a level of acceptable risk (i.e. the mix of low risk bonds and riskier stocks in a portfolio) is a good example of a judgment problem. There is no objectively "correct" level of risk, since individuals can have differing risk preferences while acting in a rational fashion.

${ }^{9}$ Also see Maciejovsky and Budescu (2007) for a discussion of teams solving the Wason selection task.
} 
teammate. There is no communication between teammates, so Buyers in the No Chat Random treatment cannot benefit from their teammates' insights let alone any synergies due to bilateral communication. Since roles are selected randomly in the No Chat - Random treatment, there is no reason to expect the subjects chosen to be Buyers to have higher ability for the task of bidding than Buyers in the Control treatment. If we assume that our subjects are self-regarding (only concerned with maximizing their own payoffs), the incentives to bid optimally are stronger when Buyers keep their entire payoff rather than sharing it with a teammate. Since $\mathrm{p}(t, \pi)$ is an increasing function of $\pi$, this implies that bids will be lower in the Control treatment than in the No Chat - Random treatment.

Hypothesis 1: Bids will be lower in Rounds $11-40$ of the Control treatment than in the No

\section{Chat - Random treatment.}

In the Chat - Random treatment, the Buyer and Seller in a team get multiple possibilities to discuss bidding. If the Seller has solved the problem by learning to bid optimally, she should communicate her insights to the Buyer. Even if the Buyer has not previously learned to bid optimally, he should recognize the optimal strategy when it is explained to him and bid optimally in the future. This is the essence of the "truth-wins" model of team decision making pioneered by Lorge and Solomon (1955). A freely communicating team should perform no worse at solving eureka problems than the most able member of the team would perform. The truth-wins model has been extensively studied in the psychology literature which finds that while teams usually outperform the average individual, they rarely meet, let alone exceed, the truth-wins benchmark (Davis, 1992; Kerr and Tindale, 2004). There have been notable exceptions to this general finding in the study of games (Cooper and Kagel, 2005). Even in the best case scenario we would not expect the truth wins model to apply exactly in the Chat

- Random treatment since teammates cannot communicate continuously. Instead, we would expect teams to meet or exceed the truth-wins benchmark in the rounds immediately following communication and then to learn at the same rate as individuals in subsequent periods. This implies that bids will be lower in the Chat - Random treatment than in the No Chat - Random treatment. ${ }^{10}$

\footnotetext{
${ }^{10}$ Risk plays a role in the takeover game. Extensive evidence exists that team decision making can shift choices under uncertainty. Initial studies found that groups choose more risky gambles than individuals ("risky shift"), but subsequent studies found evidence of cautious shifts as well (Davis, 1992). In the takeover game, choosing an optimal bid $(90 \leq \mathrm{B}<135)$ increases expected payoffs and reduces risk. Bidding in the range $90 \leq \mathrm{B}<135$ is therefore optimal for any risk neutral or risk averse agent. Play in teams does not affect the optimal bid unless some individuals or teams are risk loving. Previous studies suggest that risk loving behavior is uncommon. Holt and Laury (2002), for example, report $8 \%$ of subjects are risk loving in their low stakes sessions (less with higher stakes), and most of these are only modestly risk loving. It seems unlikely that significant shifts between individual and team play in the takeover game are driven by the small fraction of subjects that are risk loving.
} 
Hypothesis 2: Bids will be lower in Rounds 11 - 40 of the Chat - Random treatment than in the No Chat - Random treatment.

Teammates cannot discuss how to bid in the No Chat - Endogenous treatment, ${ }^{11}$ but it is no longer random who receives the role of Buyer. If the goal is to make as much money as possible, the teammates should attempt to get the most able individual in the role of Buyer since the role of Seller is trivial and, as shall be seen, it matters little who fills this role. The teammates have access to an excellent indicator for who will do a better job as the Buyer their earnings from the first ten rounds. Luck plays a role in earnings, but ten rounds are enough that luck tends to even out. There is high correlation between bidding low in the first ten rounds and earnings in the first ten rounds. ${ }^{12}$ Individuals who bid low in Rounds $1-10$ also tend to bid low in Rounds $11-40 .{ }^{13}$ If teams systematically pick the individual who earned more in Rounds $1-10$ to be the Buyer for Rounds $11-40$, they will on average bid lower and earn more in Rounds 11 - 40 than teams with randomly selected roles. Note that this does not require that teammates share any understanding of how to bid, which is largely impossible by design. All that this prediction requires is that teammates follow the simple and intuitive rule that a Buyer who did well in the first ten rounds is also likely to do well in the remaining rounds.

Hypothesis 3: Bids will be lower in Rounds 11 - 40 of the No Chat - Endogenous treatment than in the No Chat-Random treatment.

We have no firm prediction about the relative size of bids in Chat - Random and No Chat - Endogenous. If the truth wins model exactly captured how teams function with chat and if teams in No Chat - Endogenous always pick the most able individual to be the Buyer, the two treatments should yield identical bids on average. It seems unlikely that either condition will hold exactly and we have no particular theory, ex ante, about the relative departures from these predictions.

The Chat - Endogenous treatment should be the best of all worlds. The teammates get to pick who takes the critical Buyer role. In choosing roles, they are not restricted to the information they are given about each other. They are free to discuss how to bid as well as information about their respective bids in Rounds $1-10$. Given a greater ability to share information, teammates should do a better job of picking the more able individual for the

\footnotetext{
${ }^{11}$ The instructions for the short messages (100 characters) subjects send when proposing roles tell them that the messages are for commenting on this decision. No subject sent a message discussing how to bid.

${ }^{12}$ The correlation between an individual's average bid and average points earned in Rounds $1-10$ is -.599 . This is statistically significant at the $1 \%$ level $(\mathrm{t}=17.54)$.

${ }^{13}$ Looking at the Control treatment, where nothing changes between Rounds $1-10$ and Rounds $11-40$, the correlation between an individual's average bids in Rounds $1-10$ and Rounds $11-40$ is .613. This is statistically significant at the $1 \%$ level $(\mathrm{t}=9.28)$.
} 
Buyer role in the Chat - Endogenous treatment than in the No Chat - Endogenous treatment. The Chat - Endogenous treatment also gives teammates multiple opportunities to discuss the takeover game at length. If the Seller has useful insights, either initially or after a few rounds of play as a Seller, she can pass these on to the Buyer. With the advantages of better partner selection and sharing of ideas, we expect bids to be lower in Chat Endogenous than in No Chat - Endogenous.

Hypothesis 4: Bids will be lower in Rounds 11 - 40 of the Chat - Endogenous treatment than in the No Chat - Endogenous treatment.

Our prediction about the relative size of bids in the Chat - Endogenous and Chat Random treatments depends on our confidence in the truth wins model. If the truth wins model holds exactly, it should not matter which teammate takes which role in the chat treatments. A high ability Seller can always pass all of her insights about bidding along to the Buyer even if the Buyer has low ability. If this holds, no difference is predicted between the two chat treatments. However, the often times poor performance of the truth wins model suggests that Sellers will not always share their insights about bidding and the Buyers will not always follow good advice. ${ }^{14}$ If so, even with chat it should matter which teammate is selected to be the Buyer. Endogenous role assignment should increase the probability that the more able teammate (i.e. the teammate who bids lower in the first phase) becomes the Buyer. By extension, bids should be lower in Chat - Endogenous than in Chat - Random.

Hypothesis 5: Bids will be lower in Rounds 11 - 40 of the Chat - Endogenous treatment than in the Chat - Random treatment.

\section{$5 \quad$ Results}

A. Rounds 1 - 10: In all treatments, subjects begin the experiment by playing ten rounds as a Buyer facing the computer in the role of Seller. The cluster of bars on the left side of Figure 1 shows the distribution of bids for Rounds $1-10$. Bids have been broken into the same seven categories used in Table 1 to show the logic of bidding a low amount. There are four categories $(\mathrm{B}<90,135 \leq \mathrm{B}<600,900 \leq \mathrm{B}<1200$, and $\mathrm{B} \geq 1800)$ where the Buyer never earns money unless the Seller makes an error. Choices in these four categories can be regarded as an unambiguous error, but these are rare. The remaining three categories $(90 \leq \mathrm{B}$

\footnotetext{
${ }^{14}$ For inexperienced subjects, Cooper and Kagel (2011) find that about a third of the individuals who receive correct advice about how to play a game fail to follow this advice. The quality of the explanation that accompanies the advice does not affect this percentage.
} 
$<135,600 \leq \mathrm{B}<900$, and $1200 \leq \mathrm{B} \leq 1800$ ) can make money if the right value is drawn. As explained previously, only the first category $(90 \leq \mathrm{B}<135)$ has positive expected value.

\section{Figure 1 about here}

A little less than half of the bids are optimal $(90 \leq \mathrm{B}<135)$ in the first ten rounds. Many subjects immediately grasp the need to bid optimally, but many don't. This is a scenario in which team play with communication should help since there will be many matches between an individual who doesn't bid optimally with a subject who does. Of course, subjects don't fall neatly into categories of those who "get it" and those who don't. Only $10 \%$ of the subjects never bid optimally in Rounds $1-10$ and only 18\% always bid optimally. Looking at demographic effects on bidding behavior, we find that men bid significantly lower than women (average bids of 365 vs. $438 ; p<.01$ in a regression not shown here) and that subjects with the best math grade bid lower than the other subjects (average bids of 327 vs. $422 ; p<$ .01). There is no significant effect from a subject's age or German score.

B. Sellers in Rounds 11 - 40: Underlying the hypotheses developed in Section 4 is an assumption that Sellers always behave optimally (in terms of maximizing monetary payoffs), accepting bids that are strictly greater than their value and rejecting bids strictly less than their value. In the Control treatment this happens by design, but in the four treatments with subjects (rather than the computer) as Sellers in Rounds 11 - 40 we can't take this assumption for granted. If subjects playing as Sellers frequently make suboptimal decisions, differing incentives across treatments could disrupt the predicted treatment effects.

Fortunately, suboptimal decisions by Sellers are relatively rare. Define an error as rejecting a bid strictly greater than the item's value or accepting a bid strictly less than the item's value. Errors are observed for only $4 \%$ of observations in Rounds 11 - 40. Errors are more common when the bid is greater than the value ( $8 \%$ error rate), but this primarily reflects cases where the difference between the bid and value is strictly less than 5 points ( $21 \%$ error rate). Once the difference between the bid and value is weakly greater than 15 points the error rate stabilizes at $5 \%$ with little variance as the difference between the bid and value grows. ${ }^{15}$

\footnotetext{
15 The fact that some bids that yield positive profits for the Seller are rejected suggests that other-regarding preferences play some role in the game, but given the low rejection rates for any substantial profit this role seems to be minimal. Perhaps this is unsurprising as Sellers are often making large profits and are splitting profits with their teammate in the Buyer role in any case.
} 
It was inevitable that human Sellers would make at least some errors. The critical issues are whether the error rate varies across the four treatments with human Sellers and whether errors change the logic in favor of submitting an optimal bid $(90 \leq \mathrm{B}<135)$. To answer the first question, we ran a probit regression using all observations from human Sellers where an error was possible (i.e. bid $\neq$ value). Standard errors were corrected for clustering at the Seller level. The dependent variable was whether the Seller made a mistake. Independent variables included controls for the value of the item, the difference between the bid and the value (interacted with dummies for overbids and underbids), and the time period. The independent variables of interest were treatment dummies. There are no significant differences in the probability of a mistake between the four treatments with human Sellers. ${ }^{16}$

Turning to the second issue, even with Sellers' errors it remains optimal to submit a bid in the range $90 \leq \mathrm{B}<135$. Across the four treatments with human Sellers, the average payoff in Rounds $11-40$ from submitting a bid in this range was 22 points. ${ }^{17}$ The average payoff from bidding optimally is unambiguously higher than the average payoff from submitting a bid in the range $600 \leq \mathrm{B}<900$ (-91 points) or the range $1200 \leq \mathrm{B}<1800$ (-315 points). In all four treatments with human Sellers, the average payoff from submitting a bid in the range $90 \leq \mathrm{B}<$ 135 is at least 100 points higher than the average payoff from submitting a bid in the range $600 \leq \mathrm{B}<900$. The difference in incentives occurs for exactly the manner predicted by the theory, specifically that subjects who bid just enough to get the items with the middle value $(600 \leq$ B < 900) almost always get their bid accepted for low value items (93\% purchased), but almost never get to purchase high value items (2\% purchased). Understanding adverse selection remains the critical insight for choosing an optimal bid.

C. Treatment Effects for Buyers: Figure 2 shows average bids by Buyers in all five treatments. The data is broken down into ten round blocks and data is included from Rounds 1 -10 , the rounds before the treatments are in effect, to give a sense of the differing starting points for the treatments. The data for Rounds $1-10$ is taken from all subjects, including those who became Sellers in Rounds $11-40$.

Figure 2 about here

\footnotetext{
${ }^{16}$ The base was the No Chat - Random treatment. The parameter estimates for Chat - Random, No Chat Endogenous, and Chat - Endogenous are .049, .051, and -.011 respectively, with standard errors of .172, .170, and .191. None of these estimates are statistically significant.

${ }^{17}$ This is slightly higher than the theoretical prediction of 15 points due to a small number of cases where Sellers with high values accepted low bids.
} 
In Rounds 11 - 40, bids are relatively low in the Chat - Random treatment. The bids are almost as low for the No Chat - Endogenous treatment in Rounds 11 - 20, but differences between the two treatments appear in later rounds. The big surprise is how high bids are in the Chat - Endogenous treatment. We hypothesized that this treatment would yield the lowest bids, yet bids for Rounds 11 - 20 are higher in Chat - Endogenous than in Chat - Random or No Chat - Endogenous. This is more notable for the fact that bids for Rounds $1-10$ are, by chance, lower in Chat - Endogenous than in any other treatment. Over time, bids in Chat - Endogenous fall faster than in any other treatment so that bids in Rounds 31 - 40 are slightly lower in Chat - Endogenous than in the Chat - Random treatment.

\section{Table 2 about here}

The regressions reported in Table 2 are designed to provide statistical support for our observations about Figure 2. The dataset for these regressions includes all observations from our data. The dependent variable is the amount bid by the Buyer. Robust standard errors are reported in parentheses.

An obvious feature of the data is strong individual effects. To correct for these, all of the models use a linear specification with fixed effects. The fixed effects are identified from choices in Rounds $1-10$, before any of the treatments take effect. The first row of Table 2 identifies the unit being used for the fixed effects: Models 1 and 3 use fixed effects identified from early choices (Rounds $1-10$ ) by both members of a team while Models 2 and 4 use fixed effects based only on early choices by the Buyer. The different methods allow us to identify how much of the observed treatment effects are due to selection. This is relevant for the No Chat - Endogenous and Chat - Endogenous treatments where individuals who bid less in Rounds $1-10$ are presumably more likely to become Buyers. If the fixed effects are at the team level, the estimated effects for these two treatments include the impact of selection because the fixed effects correction does not account for the possibility that Buyers in the No Chat - Endogenous and Chat - Endogenous treatments bid systematically lower than their teammates in Rounds $1-10$. The estimated treatment effects will not reflect the effects of selection if the fixed effect is at the Buyer level since the regression now corrects for the early choices of individuals who were selected to be Buyers.

Model 1 is a basic regression checking whether the treatment effects are significant either due to the changing behavior of Buyers or selection into the Buyer role. The baseline is the No Chat - Random treatment, and dummies are included for the other four treatments. The 
results provide little support for Hypothesis 1. Bids in Rounds $11-40$ are lower in the Control treatment than in the No Chat - Random treatment, but the effect is weak and not statistically significant. Hypothesis 2 receives strong support from the data, as bids in Rounds 11 - 40 are significantly lower in the Chat - Random treatment than in the No Chat Random treatment. Hypothesis 3 also does well as bids in Rounds 11 - 40 are significantly lower in the No Chat - Endogenous treatment than in the No Chat - Random treatment. Hypotheses 4 and 5 receive no support from the regression analysis, as the estimated effect of the Chat - Endogenous treatment is smaller than the estimated effects for either the No Chat - Endogenous or Chat - Random treatments rather than larger as predicted. Unlike these other two treatments, the combination of chat and endogenous role selection does not lead to a significant improvement over the baseline.

In Model 2 the fixed effect is at the Buyer level, checking whether the treatments had a significant effect based solely on changes in Buyers' behavior (rather than selection). This shouldn't matter much for comparisons between treatments where roles are randomly selected, and indeed we continue to find little support for Hypothesis 1 while Hypothesis 2 still receives strong support. We do not find a significant difference between the No Chat Random and No Chat - Endogenous treatments, consistent with the treatment effect identified in Model 1 being driven by selection into the Buyer role. This is not evidence against Hypothesis 3, but instead indicates that Hypothesis 3 is holding for the predicted reason. The most striking result from Model 2 is the failure of the Chat - Endogenous treatment to decrease bids relative to the No Chat - Endogenous treatment (i.e. the estimated difference between the treatments is positive rather than negative as predicted). Our hypotheses are based on the assumption that chatting with a teammate improves a Buyer's decision making. This is true when roles are assigned randomly since, controlling for Buyer ability, bids are significantly lower in Chat - Random than No Chat - Random, but not when role assignment is endogenous. Because of this, the difference between the two chat treatments in Rounds $11-40$ is significant at the $10 \%$ level and barely misses significance at the $5 \%$ level $(\mathrm{t}=1.95 ; \mathrm{p}=.052)$.

Looking at Figure 2, it is clear that the treatment effects have a strong dynamic component. Models 3 and 4 allow for changing treatment effects by interacting the treatment dummies with dummies for ten round blocks (Rounds $11-20$, Rounds $21-30$, and Rounds 31 - 40). The base in all cases is the No Chat - Random treatment for the current ten round block. Model 3 has fixed effects at the team level while Model 4 has fixed effects at the Buyer level. The results of Model 3 largely parallel those of Model 1. The Chat - Random and No 
Chat - Endogenous treatments consistently have significant negative effects on bids, although in both cases the effect weakens over time. Hypothesis 1 does slightly better in Model 3 as the difference between No Chat - Random and the Control treatment is weakly significant for Rounds 11 - 20. The estimated effect of the Chat - Endogenous treatment is always smaller than the effects of the Chat - Random and No Chat - Endogenous treatments, although it does better over time so that by Rounds 31 - 40 the estimated effect (relative to No Chat - Random) is statistically significant.

The most notable result from Model 4 is that the difference between the two chat treatments dies out over time. The difference is significant at the 5\% level in Rounds $11-20$ $(\mathrm{t}=2.10 ; \mathrm{p}=.036)$ and at the $10 \%$ level for Rounds $21-30(\mathrm{t}=1.93 ; \mathrm{p}=.054)$, but barely has a t-stat greater than 1 for Rounds $31-40(\mathrm{t}=1.11 ; \mathrm{p} .268)$. This cannot be attributed to a floor effect, as the average bid for Rounds 31 - 40 in the Chat - Random treatment is well above 135 points, the upper end of the optimal bid range, and only 52\% of Buyers bid optimally in all of the final ten rounds. Bids could have continued to drop in the Chat Random treatment, but instead the time trend flattens out allowing the Chat - Endogenous treatment to catch up. ${ }^{18}$

In discussing bids for Rounds 1 - 10, we noted that bids were lower for men and individuals with high math scores. Using just the data from the three treatments without chat, we have run a regression including demographic information about Buyers for Rounds 11 40. The regression is an expanded version of Model 2 from Table 2 but also includes controls for gender, age, math score, and German score. These dummies are interacted with a dummy for late rounds (Rounds 11 - 40), so effects are measured controlling for the Buyer's behavior in Rounds 1 - 10. The gender effect is largely reversed, with women bidding (weakly) significantly lower in Rounds 11 - 40 relative to their bids in Rounds 1 - 10 (parameter = $50.10 ; \mathrm{t}=1.88$ ). This does not imply that women are bidding lower than men in Rounds $11-$ 40. Women are still bidding more than men (324 vs. 294), but the gap is narrowed relative to Rounds $1-10$. The parameter estimate for math is small and not statistically significant (parameter $=-7.08 ; \mathrm{t}=0.59$ ). The initial advantage of individuals with high math scores is being picked up by the fixed effects, and the lack of a significant effect in Rounds $11-40$ indicates that the advantage of individuals with high math scores holds steady over time.

\footnotetext{
${ }^{18}$ If we compare the effects of chat with random and endogenous role assignment, the effect of chat is getting weaker over time with random role assignment and stronger with endogenous role assignment. Nevertheless, even in Rounds 30 - 40 the difference between No Chat - Endogenous and Chat - Endogenous is not statistically significant $(\mathrm{t}=0.93 ; \mathrm{p}=.351)$.
} 
Including demographic variables in the regressions reported on Table 2 does not affect the conclusions.

We summarize the results up to this point by revisiting our initial five hypotheses. The following conclusions refer to bids in Rounds $11-40$.

Conclusion 1: Bids are lower in the Control treatment than in the No Chat - Random treatment, but the differences are generally small and not statistically significant. We find little support for Hypothesis 1.

Conclusion 2: Bids are lower in the Chat - Random treatment than in the No Chat Random treatment. These differences are generally large and statistically significant. The data supports Hypothesis 2.

Conclusion 3: Bids are lower in the No Chat - Endogenous treatment than in the No Chat Random treatment. These differences are large and statistically significant. The data supports Hypothesis 3.

Conclusion 4: Bids are higher in the Chat - Endogenous treatment than in either the No Chat - Endogenous or Chat Random treatments. Bids in Chat - Endogenous are not significantly lower than in the baseline (No Chat - Random). The data does not support Hypotheses 4 and 5.

Conclusion 5: Controlling for Buyer ability, including chat improves Buyer performance (i.e. lowers bids) when roles are randomly assigned but not when roles are endogenously chosen.

D. Comparing Buyers to Sellers in the Endogenous Treatments: Contrary to Hypotheses 4 and 5, bids are higher in the Chat - Endogenous treatment than in the No Chat Endogenous and Chat - Random treatments. This is surprising since teams in the Chat Endogenous treatment should have the dual advantages of chat and putting the more able individual in the role of Buyer. Comparing the results of Models 1 and 2 (or Models 3 and 4) in Table 2 suggests that selection is stronger in the No Chat - Endogenous treatment than in the Chat - Endogenous treatment. This subsection supports this conjecture by comparing the characteristics of subjects who become Buyers and Sellers in the two treatments with endogenous role assignment.

Table 3 compares Buyers and Sellers along a number of dimensions. Recall that prior to selecting a Buyer the subjects were given information about their teammate's age, gender, math score, German score, and earnings in Rounds 1 - 10. Table 3 shows, for each of these characteristics, the average values for subjects who ended up in the roles of Buyer and Seller broken down by treatment. The final row of Table 3 shows average bids in Rounds $1-10$. 
Although subjects did not know the average bids of their teammate in Rounds $1-10$, this is a natural measure of who showed more ability in the early rounds. For each characteristic in each treatment, we ran a t-test of the null hypothesis that the mean difference between the Buyer and Seller in a pair equals zero. ${ }^{19}$ The third column for each treatment reports the resulting t-stat.

\section{Table 3 about here}

For both chat treatments, none of the demographic characteristics (age, gender, math and German scores) differ significantly between Buyers and Sellers. Buyers in the No Chat Endogenous treatment had significantly higher earnings and lower bids in Rounds $1-10$ than the Sellers they were paired with. As expected, endogenous selection of roles systematically puts individuals who do well in Rounds $1-10$ into the Buyer role. This is less true for the Chat - Endogenous treatment. There is virtually no difference between the Buyers' and Sellers' earnings in Rounds 1 - 10. More importantly (since earnings are partially a matter of luck), the Buyers' average bid in Rounds $1-10$ is lower than the Sellers' average bid but the difference between Buyers and Sellers is less than half as large in the Chat Endogenous treatment as in the No Chat - Endogenous treatment. Buyers in the Chat Endogenous treatment do not have significantly lower bids in Rounds $1-10$ than the Sellers they are paired with.

Conclusion 6: Buyers in the No Chat - Endogenous treatment earn significantly more and bid significantly less in Rounds 1 - 10 than the Sellers they are paired with. Neither statement is true for the Chat - Endogenous treatment.

E. Does It Matter Who Becomes the Buyer? It would matter little whether Buyers bid less than Sellers for Rounds 1 - 10 if teams performed the same regardless of which teammate took which role. Figure 3 shows otherwise. This figure compares the average bid in Rounds $11-40$ for teams where the teammate who bid (strictly) lower on average in Rounds $1-10$ becomes the Buyer with teams where the teammate who bid lower becomes the Seller. The data is subdivided into the two treatments with teams and no chat (No Chat - Random and No Chat - Endogenous) and the two treatments with teams and chat (Chat - Random and Chat - Endogenous).

\footnotetext{
${ }^{19}$ The number of observations for each test is 60 , the number of pairs in each treatment. An observation consists of the difference between the Buyer and Seller in a pair for the characteristic in question.
} 


\section{Figure 3 about here}

In both cases the average bid for Rounds 11 - 40 is lower when the teammate who bid lower in Rounds $1-10$ is given the role of Buyer. The effect is quite a bit stronger in the treatments without chat than in those with chat. With chat, a Seller who understands the benefits of bidding low can pass this understanding on to the Buyer. This should lead to lower bids and average bids depending less on the identity of the Buyer with chat, exactly the patterns observed in Figure 3. The extreme case of this is the truth wins model, which predicts that the identity of the Buyer is irrelevant in the treatments with chat because Buyers and Sellers perfectly share insights, implying teams perform no worse than their most able member. The data shown in Figure 3 is not consistent with the truth wins model, but it would be surprising if teams performed as well as the truth wins benchmark in our experiment since teammates only talk once every ten rounds. ${ }^{20}$

\section{Table 4 about here}

The regressions shown in Table 4 put the preceding observations on a firm statistical footing and further explore the performance of the truth wins model. For both regressions the dependent variable is a team's average bid for Rounds $11-40 .{ }^{21}$ Model 1 includes data from all four treatments with teams. The independent variables are a dummy for the two treatments with chat, an interaction between a dummy for treatments without chat and a dummy for teams where the Buyer is the teammate who bid lower (on average) in Rounds $1-10$, and an interaction between a dummy for treatments with chat and a dummy for teams where the Buyer is the teammate who bid lower (on average) in Rounds $1-10$. The parameter estimate for the first of the interaction terms is large and significant at the $1 \%$ level. Not surprisingly, bids in Rounds $11-40$ are very sensitive to the Buyer's identity when the teammates cannot communicate. The parameter estimate for the second interaction term is smaller, but still

\footnotetext{
${ }^{20}$ Teammates actually observe earnings for Rounds $1-10$ rather than bids. If we use earnings in Rounds $1-10$ rather than bids in Rounds 1 - 10 to separate teams into categories for Figure 3, we get a similar pattern (teams who end up with the player with higher earnings as the Buyer bid less in Rounds 11 - 40) but the magnitude of the effect is weakened, especially with chat. This reflects the random element of earnings, as a subject who bids optimally but receives a bad draw on values may not have particularly high earnings.

${ }^{21}$ Fixed effects are not used here because these would be collinear with the independent variables. As an extreme version of controlling for individual effects, we have used the average bid in Rounds $11-40$ for each Buyer as a single observation. We have run equivalent regressions where each bid is an observation, giving us 30 bids per Buyer. We correct for the individual effects by clustering at the Buyer level. This approach yields results that are essentially identical to those reported in Table 4.
} 
significant at the 5\% level. Consistent with our impression from Figure 3, who becomes the Buyer is less important when teammates can chat, but still matters.

Model 2 only includes data from the two treatments with chat. The independent variables are the Buyer's and Seller's average bids for Rounds $1-10$ interacted with dummies for the Buyer being the low bidder (on average) in Rounds $1-10$ and the Seller being the low bidder in Rounds $1-10$. (Note that we are referring to the Seller who is the Buyer's teammate, not one of the Sellers he is playing against.) Under the truth wins model, a team's performance should be equivalent to the performance of its more able member. This implies that bids in Rounds $11-40$ should depend more strongly on the bids in Rounds $1-10$ of the teammate who bid lower (and hence is presumably more able). When the Buyer was the low bidder, this prediction is confirmed. The estimate for the Buyer's average bid in Rounds $1-10$ is significant at the 5\% level while the estimate for the Seller's average bid is smaller and not significant. The results do not look as good for the truth wins model if the Seller was the low bidder. The estimate for the Buyer's average bid is now significant at the $1 \%$ level. The effect of the Seller's average bid once again is small and not significant. Even if the Seller was the more able bidder in Rounds $1-10$ and the Seller can communicate her insights with the Buyer, bids in Rounds 11 - 40 are more strongly influenced by the Buyer's early behavior than the Seller's. Moreover, the relationship between bids in Rounds $11-40$ and bids by the Buyer and Seller in Rounds 1 - 10 does not depend on whether the Buyer or the Seller bid lower in Rounds 1 - 10. "Buyer wins" would be a more accurate description of our data than "truth wins". It follows that even with chat it matters which teammate is chosen as the Buyer. Conclusion 7: Both without and with chat, teams where the Buyer bid lower than the Seller in Rounds 1 - 10 have lower bids in Rounds 11 - 40. Even with chat, bids in Rounds 11 - 40 depend far more strongly on the Buyer's behavior in Rounds 1 - 10 than the Seller's early behavior.

F. Content of Conversations: We would expect bids in Rounds $11-40$ to be equal in the Chat - Random and Chat - Endogenous treatments if the only problem in the Chat Endogenous treatment was a failure to select the more able individual as the Buyer. The fact that bids are higher in the Chat - Endogenous treatment, significantly so after controlling for selection into the Buyer role, suggests that something else must be going on. To determine what that something else might be, we turn to the content of the conversation between teammates. 
We focus on the conversations that took place between Round 10 and Round 11. In both treatments with chat, this time period gave teammates an opportunity to discuss how the takeover game should be played. In the Chat - Endogenous treatment it also gave them an opportunity to discuss who should take which role. Recall that subjects were given five minutes to chat and could not move on to the next stage of the experiment until the five minutes had elapsed. The goal was to give subjects adequate time to discuss how to bid and (when relevant) role selection without any incentive to rush through the conversation to make the experiment shorter. Subjects indeed chatted extensively, with the average team sending 25.0 messages during the five minutes. Teams in the Chat - Random treatment sent slightly more messages on average than teams in the Chat - Endogenous treatment, 26.2 vs. 23.8 $(\mathrm{t}=1.41 ; p>0.1)$, even though teams in the Chat - Random treatment did not need to discuss who took which role.

Looking at what teams said, we see significant differences between the two chat treatments. We coded every team for whether they discussed how to bid and, as a subcategory of this, if they specifically discussed the benefits of bidding low. The coding was initially done independently by two research assistants. We then had the two coders discuss all the discrepancies in the coding and agree on a single decision for coding. This final coding was used for the analysis to be reported in the following. We allowed for the possibility that even after discussion the coders would not agree on a coding. In these rare cases ( 1 observation) the coding was assigned a value of $1 / 2$. Using a single coding simplifies our discussion of the chat content but has little effect on our conclusions since there was a high degree of agreement between the two initial codings. ${ }^{22}$

In the Chat - Random treatment, $78 \%$ of the teams discussed how to bid, but in the Chat - Endogenous treatment only $61 \%$ of the teams did so. This difference is significant at the $5 \%$ level $(\mathrm{t}=2.12)$. A similar pattern occurs if we look at teams that specifically discussed bidding low. This occurred more frequently in the Chat - Random treatment (63\%) than in the Chat - Endogenous treatment (35\%) with the difference significant at the $1 \%$ level $(\mathrm{t}=3.12)$. Not only do teams with chat do a poor job of endogenously selecting roles, they also do a poor job of discussing how to play the takeover game. This parallels our previous observation that, controlling for Buyer ability, chat did not improve Buyers' choices (i.e. lower bids) when role assignment is endogenous.

\footnotetext{
${ }^{22}$ The cross-coder correlation was 0.55 for the category "discussed how to bid" and 0.49 for "bidding low", both significant at the 5\% level. An average cross-coder correlation of around 0.5 (as in our case) is well accepted in social psychology (see, e.g., Orbell et al., 1988).
} 
One possible explanation for the paucity of substantive conversations in the Chat Endogenous treatment is the time constraint. Even with the generous time provided for chat, if teams spend most of this time discussing who should take which role it may leave insufficient time to discuss how to bid. Two features of the data argue that the time constraint is not playing an important role in reducing discussions of bidding. First, the chat content for teams that talk up to the time constraint isn't much different from those who don't. The 41 teams in the Chat - Endogenous treatment that sent a message in the last 20 seconds (and hence are plausibly time constrained) were slightly, but insignificantly, more likely than average to have discussed how to bid (65\% vs. $67 \%$ for all 60 teams) and to have specifically discussed bidding low (37\% vs. 35\% for all 60 teams). Second, the vast majority of the discussions on role selection were short. The most common pattern was that one of the teammates proposed a role, the other accepted the proposal, and they moved on to other things. ${ }^{23}$ The rapid selection of roles left ample time to discuss bidding, yet many teams failed to do so.

The relative failure of teams in the Chat - Endogenous treatment to discuss bidding in general, especially bidding low, largely explains why bids are significantly higher than in the Chat - Random treatment after controlling for selection into the Buyer role. With Buyer fixed effects, the estimated difference between the two chat treatments in Rounds $11-40$ is 91.26 with a robust standard error of 46.86 (see discussion of Model 2 in Table 2). If this regression is modified to include a control for whether the team discussed bidding low, the estimated difference drops to 47.37 with a robust standard error of 45.58 . The difference between the treatments is halved and is no longer statistically significant. Likewise, with Buyer fixed effects, the estimated difference between the chat treatments in Rounds $11-20$ is 111.40 with a robust standard error of 53.02 (see Model 4 in Table 2). Adding a control for whether the team discussed bidding low reduces the estimated difference to 67.52 with a robust standard error of 50.21. Again, the estimated difference is no longer significant. Hence, even with a fairly crude control for what is being said between Rounds 10 and 11, a large fraction of the higher bids in Chat - Endogenous relative to Chat - Random can be accounted for.

\footnotetext{
${ }^{23}$ The following exchange is typical:

Subject A: Seller or buyer?

Subject B: buyer

Subject A: ok

Subject B: ok

Subject B: and you?

Subject A: I try it as seller then

Subject B: perfect
} 
Conclusion 7: Teams in Chat - Endogenous send fewer messages between Rounds 10 and 11, are significantly less likely to discuss bidding, and are significantly less likely to discuss bidding low than teams in Chat - Random. Controlling for differences in chat content explains a large fraction of why bids are higher in Chat - Random than in Chat Endogenous.

Examining the content of messages in more detail also gives us insight into why teams in Chat - Endogenous do a poor job of selecting the right person to be the Buyer. We define a team as having had a "good negotiation" if one of the teammates proposed an assignment of roles, the other teammate accepted this proposal, and the players actually ended up being assigned to the agreed upon roles. Out of 60 teams in Chat - Endogenous, only 36 had good negotiations. The teams that had good negotiations generally did a decent job of assigning the right person to the right role - the player who bid lower in Rounds 1 - 10 was assigned the Buyer role for 25 of these teams and the average bid in Rounds $1-10$ of Buyers was 316 versus 396 for Sellers. However, 24 teams did not have a good negotiation. In 8 of these teams none of the team members proposed a role during the chat conversation. In another 8 the teammates didn't reach an agreement. Finally, there are 8 teams where the teammates reached an agreement but didn't end up in the agreed upon roles; in other words, at least one teammate reneged on the agreement. The teams that don't have good negotiations do a poor job of getting the right person in the Buyer role. The teammate who bid lower in Rounds 1 10 was assigned the Buyer role for 14 of these 24 teams and the average bid in Rounds $1-10$ of Buyers was 402 versus 426 for Sellers. The poor assignment of teammates to roles in Chat - Endogenous is largely due to failure to reach and abide by agreements on roles.

These failures cannot easily be attributed to subjects failing to understand that they were supposed to discuss role assignment or that they would be choosing roles endogenously. After all, teams did well at role assignment in the No Chat - Endogenous treatment. The instructions about role assignment are similar for the two treatments. More teams sent messages about role assignment in Chat - Endogenous (54 out of 60 teams) ${ }^{24}$ than in No Chat - Endogenous ( 8 out of 60 teams), and the length of the discussions was greater (for obvious reasons) in Chat - Endogenous. While teams seem to understand they need to assign roles, they don't necessarily view this as a critical decision. Their discussions of role assignment are typically brief and miss basic points. It is striking that not a single team discussed the importance of picking the right person (i.e. the person who had performed better

\footnotetext{
${ }^{24}$ This is more than the number of teams where a proposal about role assignments was made because there were two teams in Chat - Endogenous that discussed role assignment without ever making any proposals.
} 
in Rounds 1 - 10) for the role of Buyer. Having to discuss bidding and role assignment degrades the quality of teams' discussions of both issues.

\section{Conclusion}

The primary purpose of our study was to investigate the relationship between how roles are assigned within a work team and team performance. As expected, we found that teams perform better when roles are assigned endogenously or teammates are allowed to chat about their decisions. The big surprise is that the interaction effect between endogenous role assignment and chat harms team performance, leading to higher bids rather than lower bids as expected. Digging deeper, teams in the Chat - Endogenous treatment both do a poor job of selecting which teammate should take on the Buyer role and in discussing how to bid.

Time constraints do not provide a good explanation for the relatively poor quality of the discussions in the Chat - Endogenous treatment, but time is not the only constraint teams may face. There is extensive evidence from the psychology literature on "ego depletion" (e.g. Baumeister, Bratslavsky, Muraven, and Tice, 1998; Schmeichel, Vohs, and Baumeister, 2003) that individuals only have a limited budget of cognitive resources. If they are forced to expend some of their cognitive resources on one task, they are less able to perform other tasks. For example, individuals who must exercise self control to eat a healthy food (radishes) when a more tempting alternative (chocolate) is available subsequently expend less effort and perform worse at solving logic problems than subjects in control treatments. The effect of ego depletion is particularly strong for intellective tasks. Unlike the Chat - Random and No Chat - Endogenous treatments, in the Chat - Endogenous treatment subjects must deal with multiple intellective tasks (discussing how to bid and the best way to assign roles) while exercising self-control (as seen through the strong tendency to defer to teammates' requests). This is exactly the sort of environment that typically depletes cognitive resources, leading to poor performance on logic tasks like bidding in the takeover game. We conjecture that ego depletion plays an important role in driving our primary results and hope to collect direct evidence testing this hypothesis in future research.

Our results sound a cautionary note about increased worker participation. Increased worker participation has obvious positive aspects. Workers who feel greater connection with the group and greater accountability to their work group are likely to work harder and think more carefully about the problems facing their work group. Workers also often have valuable information that can be passed on to their employers if they are given an opportunity. However, allowing workers to play a greater role has the side effect of increasing their 
cognitive load. If individuals only have a limited amount of cognitive energy to expend, this risks reducing their performance at all tasks. Future researchers need to think carefully about what tasks are best handled by a manager and what tasks are best left to workers.

Our study is not intended to find the optimal method of assigning teammates to roles. In designing our experiments, our goal was to examine how endogenous role assignment links to team performance and whether endogenous role assignment is unambiguously positive for teams in settings where role assignment is important. The experimental design was tailored to this goal, choosing a task that strongly emphasizes the importance of role selection and only allowing extreme methods of role allocation, either completely random and exogenous or completely controlled by team members. In future research we plan to explore alternative methods of selecting roles that combine the strengths of endogenous role selection with the strengths of having a manager responsible for role selection as well as looking at mechanisms for role assignment in a broader selection of environments. 


\section{References}

Baumeister, R. F., Bratslavsky, E., Muraven, M. and Tice, D. M. (1998). Ego Depletion: Is the Active Self a Limited Resource? Journal of Personality and Social Psychology, 74(5): 1252-1265.

Bereby-Meyer, Y. and Grosskopf, B. (2007). Overcoming the Winner's Curse: An Adaptive Learning Perspective. Journal of Behavioral Decision Making, 21(1): 15-27.

Blinder, A. S. and Morgan, J. (2005). Are Two Heads Better Than One? Monetary Policy by Committee. Journal of Money, Credit and Banking, 37(5): 789-811.

Bornstein, G. and Yaniv, I. (1998). Individual and Group Behavior in Ultimatum Games: Are Groups More "Rational” Players? Experimental Economics, 1(1): 101-108.

Casari, M., Zhang, J. and Jackson, C. (2010). Do Groups Fall Prey to the Winner's Curse? IEW Working Paper 504. Institute for Empirical Research in Economics - University of Zurich.

Charness, G. and Jackson, M. O. (2007). Group Play in Games and the Role of Consent in Network Formation. Journal of Economic Theory 136(1): 417-445.

Charness, G. and Levin, D. (2009). The Origin of the Winner's Curse: An Experimental Study. American Economic Journal: Microeconomics, 1(1): 207-236.

Chow, T. and Cao, D. (2008). A Survey Study of Critical Success Factors in Agile Software Products. Journal of Systems and Software, 81(6): 961-971.

Cooper, D. J. and Kagel, J. H. (2005). Are Two Heads Better Than One? Team versus Individual Play in Signaling Games. American Economic Review, 95(3): 477-509.

Cooper, D. J. and Kagel, J. H. (2011). When are Two Heads Better than One?, FSU Working Paper.

Davis, J.H. (1992). Some Compelling Intuitions about Group Consensus Decisions. Theoretical and Empirical Research and Interpersonal Aggregation Phenomena: Selected Examples 1950 - 1990. Organizational Behavior and Human Decision Processes, 52: 338.

Fischbacher, U. 2007. z-Tree: Zurich Toolbox for Readymade Economic Experiments, Experimental Economics, 10(2): 171-178.

Greiner, B. (2004). An Online Recruiting System for Economic Experiments.” In: Kurt Kremer, Volker Macho (eds.). Forschung und wissenschaftliches Rechnen 2003. GWDG Bericht 63, Goettingen: Gesellschaft fuer wissenschaftliche Datenverarbeitung: 79-93. 
Grosskopf, B., Bereby-Meyer, Y. and Bazerman, M. (2008). On the Robustness of the Winner's Curse Phenomenon. Theory and Decision, 63(4): 389-418.

Holt, C. A., and Laury, S. A. (2002). Risk Aversion and Incentive Effects. American Economic Review, 92(5): 1644-1655.

Ichniowski, C. and Shaw, K. (1999). The Effects of Human Resource Management Systems on Economic Performance: An International Comparison of U.S. and Japanese Plants. Management Science, 45(5): 704-721.

Kerr, N. L., and Tindale, R. S. (2004). Group Performance and Decision Making, Annual Review of Psychology, 55: 623-655.

Kocher, M. G. and Sutter, M. (2005). The Decision Maker Matters: Individual versus Group Behavior in Experimental Beauty-Contest Games. Economic Journal, 115(500): 200-223.

Lorge, I. and Solomon, H. (1955). Two Models of Group Behavior in Eureka-Type Problems, Psychometrika, 20(2): 139-148.

Luhan, J. W., Kocker, M. G. and Sutter, M. (2009). Group Polarization in the Team Dictator Game Reconsidered. Experimental Economics, 12(1): 26-41.

Maciejovsky, B. and Budescu. D. V. (2007). Collective Induction Without Cooperation? Learning and Knowledge Transfer in Cooperative Groups and Competitive Auctions. Journal of Personality and Social Psychology, 92(5): 854-870.

Orbell, J. M., Dawes, R. M. and Van de Kragt, A. J. C. (1988), Explaining DiscussionInduced Cooperation. Journal of Personality and Social Psychology 54: 811-819.

Patt, A. and Zeckhauser, R. (2000). Action Bias and Environmental Decisions. Journal of Risk and Uncertainty, 21(1): 45-72.

Samuelson, W.F. and Bazerman, M. H. (1985). The Winner's Curse in Bilateral Negotiations, in V. Smith (Ed.), Research in Experimental Economics (pp. 105-137), Volume 3, Greenwich, CT: JAI Press.

Schmeichel, B. J., Vohs, K. D. and Baumeister, R. F. (2003). Intellectual Performance and Ego Depletion: Role of the Self in Logical Reasoning and Other Information Processing. Journal of Personality and Social Psychology, 85(1): 33-46.

Wason, P. C. (1966). Reasoning. In B. Foss (Ed.), New horizons in psychology (pp. 135151). Harmondsworth, Middlesex, United Kingdom: Penguin Books. 
Tables and Figures

Table 1: Bidding strategies

\begin{tabular}{|c|c|c|c|c|c|}
\hline \multirow{2}{*}{ Bid } & \multicolumn{3}{|c|}{ Value } & \multirow{2}{*}{$\begin{array}{c}1.5 * \text { Expected } \\
\text { Value if Accepted }\end{array}$} & \multirow{2}{*}{ Ever Profitable } \\
\hline & 90 & 600 & 1200 & & \\
\hline Bid $<90$ & Reject & Reject & Reject & N/A & No \\
\hline $90 \leq \operatorname{Bid}<135$ & Accept & Reject & Reject & 135 & Yes \\
\hline $135 \leq \mathrm{Bid}<600$ & Accept & Reject & Reject & 135 & No \\
\hline $600 \leq \mathrm{Bid}<900$ & Accept & Accept & Reject & 517.5 & Yes \\
\hline $900 \leq \mathrm{Bid}<1200$ & Accept & Accept & Reject & 517.5 & No \\
\hline $1200 \leq \mathrm{Bid}<1800$ & Accept & Accept & Accept & 945 & Yes \\
\hline $\mathrm{Bid} \geq 1800$ & Accept & Accept & Accept & 945 & No \\
\hline
\end{tabular}


Table 2: Regressions for Treatment Effects

\begin{tabular}{|c|c|c|c|c|}
\hline Fixed Effects & $\begin{array}{l}\text { Model } 1 \\
\text { Team }\end{array}$ & $\begin{array}{c}\text { Model } 2 \\
\text { Buyer }\end{array}$ & $\begin{array}{l}\text { Model } 3 \\
\text { Team }\end{array}$ & $\begin{array}{c}\text { Model } 4 \\
\text { Buyer }\end{array}$ \\
\hline Rounds $11-40 *$ Control & $\begin{array}{l}-47.68 \\
(32.15)\end{array}$ & $\begin{array}{l}-15.27 \\
(33.14)\end{array}$ & & \\
\hline $\begin{array}{l}\text { Rounds } 11-40 * \\
\text { Chat - Random }\end{array}$ & $\begin{array}{l}-101.01^{* * *} \\
(37.20)\end{array}$ & $\begin{array}{l}-87.21^{* *} \\
(43.91)\end{array}$ & & \\
\hline $\begin{array}{c}\text { Rounds } 11-40 * \\
\text { No Chat - Endogenous }\end{array}$ & $\begin{array}{l}-101.27^{* * * *} \\
(35.86)\end{array}$ & $\begin{array}{c}-3.65 \\
(37.77)\end{array}$ & & \\
\hline $\begin{array}{l}\text { Rounds } 11-40 * \\
\text { Chat - Endogenous }\end{array}$ & $\begin{array}{l}-57.12 \\
(36.26)\end{array}$ & $\begin{array}{c}4.04 \\
(41.62)\end{array}$ & & \\
\hline Rounds $11-20 *$ Control & & & $\begin{array}{l}-61.26^{*} \\
(32.98)\end{array}$ & $\begin{array}{c}28.84 \\
(33.29)\end{array}$ \\
\hline $\begin{array}{l}\text { Rounds } 11-20 * \\
\text { Chat - Random }\end{array}$ & & & $\begin{array}{l}-99.69^{* *} \\
(44.94)\end{array}$ & $\begin{array}{l}-85.89^{*} \\
(47.46)\end{array}$ \\
\hline $\begin{array}{c}\text { Rounds } 11-20 * \\
\text { No Chat - Endogenous }\end{array}$ & & & $\begin{array}{c}-123.54^{* * *} \\
(37.85)\end{array}$ & $\begin{array}{l}-25.92 \\
(38.24)\end{array}$ \\
\hline $\begin{array}{l}\text { Rounds } 11-20 * \\
\text { Chat - Endogenous }\end{array}$ & & & $\begin{array}{l}-35.65 \\
(45.12)\end{array}$ & $\begin{array}{c}25.51 \\
(45.24)\end{array}$ \\
\hline Rounds $21-30 *$ Control & & & $\begin{array}{l}-42.29 \\
(36.96)\end{array}$ & $\begin{array}{c}-9.87 \\
(38.47)\end{array}$ \\
\hline $\begin{array}{c}\text { Rounds } 21-30 * \\
\text { Chat - Random }\end{array}$ & & & $\begin{array}{c}-114.73^{* * *} \\
(41.12)\end{array}$ & $\begin{array}{r}-100.94^{* *} \\
(48.10)\end{array}$ \\
\hline $\begin{array}{c}\text { Rounds } 21-30 * \\
\text { No Chat }- \text { Endogenous }\end{array}$ & & & $\begin{array}{c}-106.62^{* * *} \\
(38.31)\end{array}$ & $\begin{array}{c}-9.00 \\
(41.20)\end{array}$ \\
\hline $\begin{array}{c}\text { Rounds } 21-30 * \\
\text { Chat - Endogenous }\end{array}$ & & & $\begin{array}{l}-55.47 \\
(43.17)\end{array}$ & $\begin{array}{c}5.70 \\
(50.41)\end{array}$ \\
\hline Rounds $31-40 *$ Control & & & $\begin{array}{l}-39.50 \\
(36.51)\end{array}$ & $\begin{array}{c}-7.08 \\
(37.32)\end{array}$ \\
\hline $\begin{array}{c}\text { Rounds } 31-40 * \\
\text { Chat - Random }\end{array}$ & & & $\begin{array}{l}-88.61^{* *} \\
(40.63)\end{array}$ & $\begin{array}{l}-74.81 \\
(49.55)\end{array}$ \\
\hline $\begin{array}{c}\text { Rounds } 31-40 * \\
\text { No Chat }- \text { Endogenous }\end{array}$ & & & $\begin{array}{l}-73.64^{*} \\
(43.55)\end{array}$ & $\begin{array}{c}23.98 \\
(45.36)\end{array}$ \\
\hline $\begin{array}{c}\text { Rounds } 31-40 * \\
\text { Chat - Endogenous }\end{array}$ & & & $\begin{array}{l}-80.25^{* *} \\
(38.20)\end{array}$ & $\begin{array}{l}-19.08 \\
(44.95)\end{array}$ \\
\hline
\end{tabular}

Notes: All regressions include 16,480 observations from 592 individuals (352 teams). Robust standard errors are reported in parentheses. Three $(* * *)$, two $(* *)$, and one $(*)$ stars indicate statistical significance at the $1 \%, 5 \%$, and $10 \%$ levels respectively. 
Table 3: Average Characteristics of Buyers and Sellers

\begin{tabular}{|c|c|c|c|c|c|c|}
\hline & \multicolumn{3}{|c|}{ No Chat - Endogenous } & \multicolumn{3}{|c|}{ Chat - Endogenous } \\
\hline & Buyer & Seller & $|t-s t a t|$ & Buyer & Seller & t-stat \\
\hline Age (in categories) ${ }^{\mathrm{a}}$ & 4.63 & 4.93 & 0.89 & 5.00 & 4.62 & 1.07 \\
\hline Gender $^{\mathrm{b}}$ & .583 & .483 & 1.14 & .533 & .467 & 0.68 \\
\hline Math Score & 2.33 & 2.55 & 1.18 & 2.33 & 2.42 & 0.46 \\
\hline German Score $^{c}$ & 2.18 & 2.20 & 0.11 & 2.33 & 2.50 & 1.26 \\
\hline $\begin{array}{c}\text { Earnings } \\
\text { Rounds } 1-10^{\mathrm{d}}\end{array}$ & -346 & -810 & $2.25^{* *}$ & -363 & -343 & 0.09 \\
\hline Bid, Rounds. 1 - 10 & 364 & 494 & $3.24^{* * *}$ & 351 & 408 & 1.36 \\
\hline
\end{tabular}

Notes: Three (***), two $(* *)$, and one $(*)$ stars indicate statistical significance at the $1 \%, 5 \%$, and $10 \%$ levels respectively.

a Age was coded as follows: $0=18$ years or younger; $1=19$ years; $2=20$ years; $3=21$ years; $4=22$ years; $5=23$ years; $6=24$ years; $7=25$ years; $8=26$ years or older.

${ }^{\mathrm{b}}$ Gender was coded as follows: $0=$ Male; $1=$ Female.

${ }^{\mathrm{c}}$ Lower grades are better in the Austrian school system. Grades were coded from 1 to 5.

${ }^{\mathrm{d}}$ Earnings do not include the starting capital of 3000 experimental points. 
Table 4: Does the Buyer's Identity Matter?

\begin{tabular}{ccc}
\hline & Model 1 & Model 3 \\
Dataset & All Team Sessions & Chat Sessions \\
\# Subjects & 240 & 120 \\
\hline Chat & $-55.79^{* * *}$ & \\
No Chat * & $(25.16)$ & \\
Buyer Low Bidder & $-82.37^{* * *}$ \\
Chat * & $(17.74$ & \\
Buyer Low Bidder & $-35.87^{* *}$ & \\
Bug. Bid, Rounds 1-10 & $(18.19)$ & $.286^{* *}$ \\
Buyer Low Bidder & & $(.140)$ \\
Buyer's & \\
Sellers's Avg. Bid, Rounds 1-10 & & $(.095)$ \\
Buyer Low Bidder & & $.295^{* * *}$ \\
Buyer's Avg. Bid, Rounds 1-10 & & $(.100)$ \\
Seller Low Bidder & .141 \\
Sellers's Avg. Bid, Rounds 1-10 & & $(.169)$ \\
Seller Low Bidder &
\end{tabular}

Notes: Robust standard errors are reported in parentheses. Three $(* * *)$, two $(* *)$, and one $(*)$ stars indicate statistical significance at the $1 \%, 5 \%$, and $10 \%$ levels respectively. 

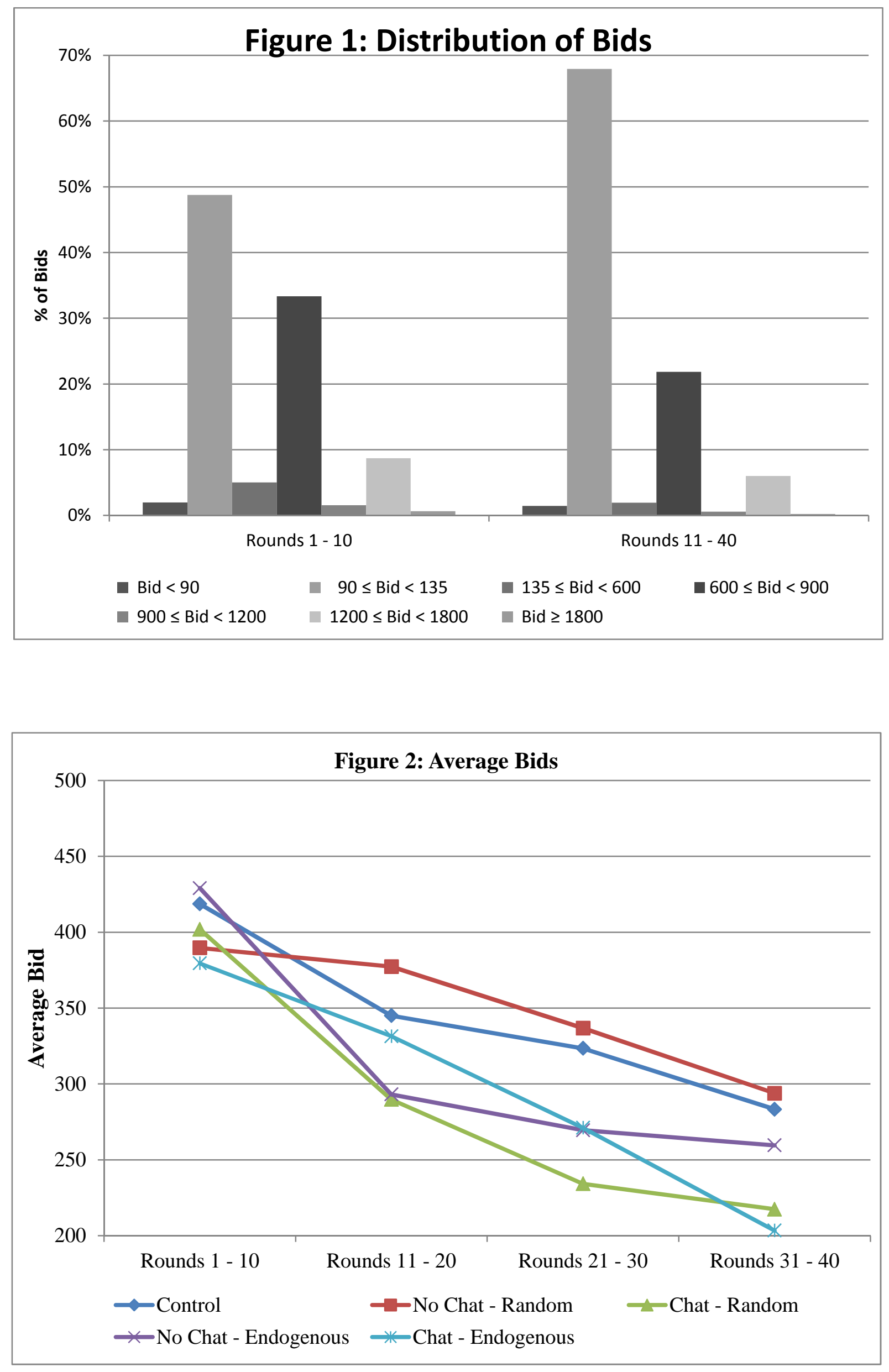


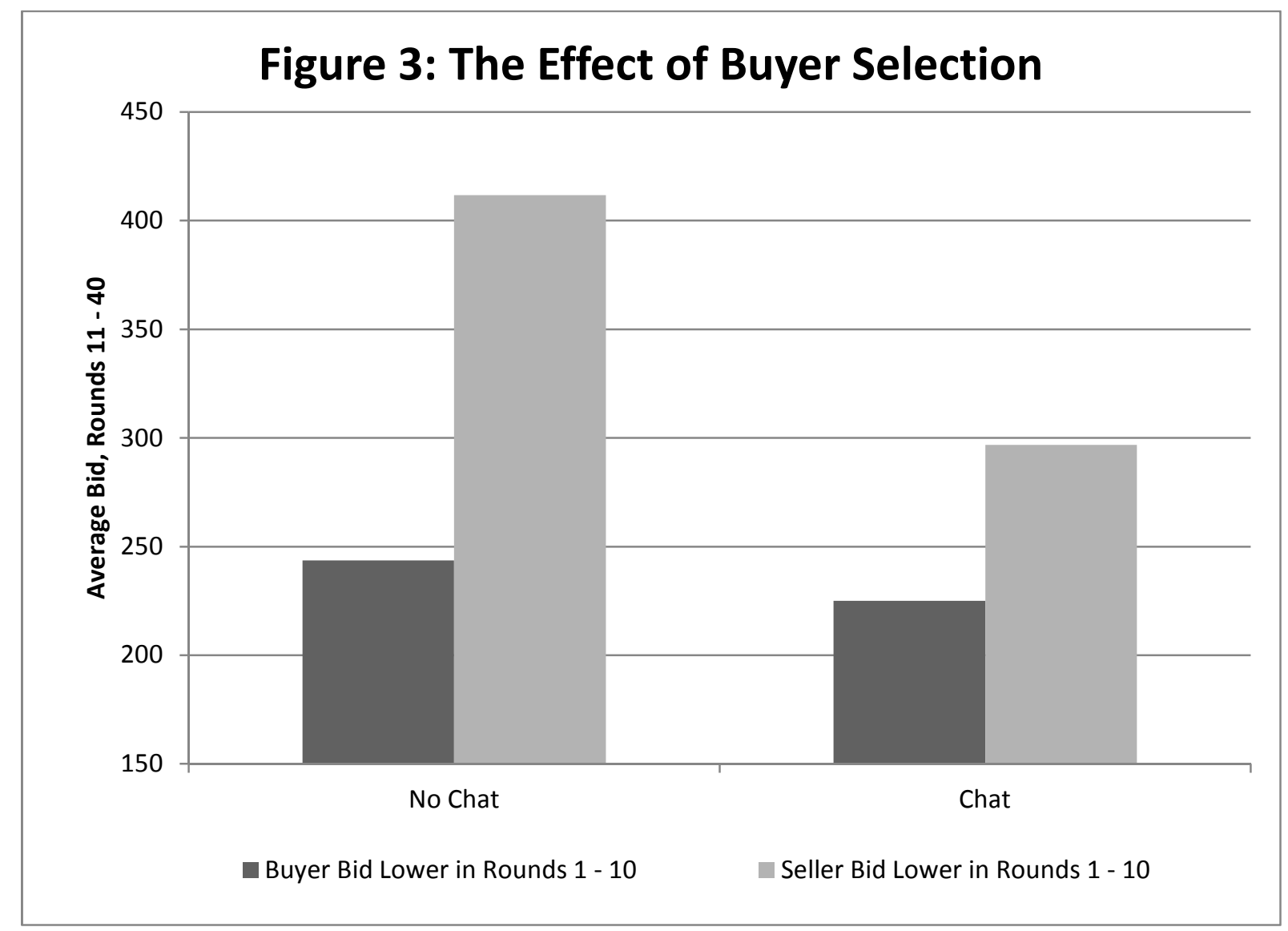


Not Intended for Publication

Appendix - Experimental instructions

\section{Instructions for the experiment}

Welcome to this experiment! Thank you for taking your time to participate. Please refrain from talking to other participants until the experiment is finished. In case you have any questions after we have read through the instructions, please raise your hand and an experimenter will come to your seat and will answer it.

\section{Two parts of the experiment}

This experiment has two parts. In the following, you'll get the instructions for part 1 . The instructions for part 2 will be distributed at the end of part 1.

\section{Instructions for part 1}

\section{Initial endowment}

For part 1 you get an initial endowment of $12 €$. This endowment will be included in the profit for the first period.

\section{Number of periods}

Part 1 has 10 periods. In each single period, you can buy cards, the value of which will be determined randomly. We will now explain the exact procedure within each period.

\section{Submitting bids for a card in each period}

In each period, you can submit a bid for a card that has a certain nominal value. This nominal value will be determined randomly in each period. A card can have three possible nominal values (in points):

- 90

- 600

- 1,200

Each of these three values is equally likely to be drawn. In other words, this means that each nominal value will be realized with a probability of $1 / 3$. The realization of nominal values is independent across periods. This means that the realization in the preceding period has no influence whatsoever on the realization in the current period.

You will submit a bid for a card before you learn about the realized nominal value. The bid must be an integer number in the interval from 0 (zero) to 2,000 (with 0 and 2,000 included in the interval). The actual nominal value will be determined after you have submitted your bid.

\section{Profits from bids}

If your bid is larger or equal to the nominal value of the card, then you buy the card. In this case you get $150 \%$ of the card's nominal value. However, you also have to buy the card in this case.

If your bid is smaller than the nominal value, then you don't buy the card. This means that no transaction takes place, and you don't earn anything in this case.

\section{An example:}


Consider the case in which you bid 712 for the card:

1. Assume that the card's nominal value is 600. In this case, you buy the card. This means that you receive $600 * 1.5=900$ points. You have to pay 712 according to your bid. This yields a profit of 188 (= value of 900 to you as the buyer - bid of 712).

2. Assume that the card's nominal value is 90 . Then you buy the card and it is worth 135 for you $(=90 * 1.5)$. In this case your profit is negative: $-577(=135-712)$.

3. Assume that the card's nominal value is 1,200 . Then you don't buy the card and this period's profit is 0 for you.

At the end of each period you will see an "outcome screen", on which there is a list that contains for all previous periods the following information: your bid, the nominal value of the card, whether you have bought the card or not, and the profit.

At the end the experiment all profits of each period will be added up and paid to you. The exchange rate of points earned in the experiment into Euros is the following:

\subsection{Points $=0.01 €$.}

\section{Some examples to be worked on before the start of part 1}

Assume you bid 128 and the card's nominal value is 90 . How much do you earn?

Assume you bid 767 and the card's nominal value is 1,200 . How much do you earn?

Assume you bid 791 and the card's nominal value is 90 . How much do you earn? 


\section{Instructions for part 2}

\section{Roles of buyers and sellers}

Part 2 is similar to part 1 . However, in this part there will be buyers and sellers of cards. The task that each role has to perform is explained below.

\section{Number of periods}

Part 2 has 30 periods.

\section{Fixed pairs and how to assign roles}

It is important in this part that at the beginning of it, fixed pairs of buyers and sellers will be formed. These pairs will remain fixed throughout the whole part 2.The fixed pairs have a strong influence on the profits from this part (see more on this at the end of the instructions for part 2!).

At the beginning of part 2 you will have an option to exchange messages with the partner in your pair. For this purpose, we have installed an instant-messaging-program in the software. In order to use it, you have to write your message into the empty row at the bottom of your screen, and then you have to push "Enter" to send your message to your partner. Once you send you send a message, it is shown on your partner's screen and on your screen (above the empty row). Note that no other participant in the room can see your message.

You can send any message you like, expect for the following limitations:

- Please do not reveal your identity. This also includes information that allows your personal identification.

- Please do not use any abusive language.

Before you can start using the instant-messaging-program, you'll receive some information about the partner in your pair. More precisely, you'll be informed about his or her age, gender, field of study, population of hometown, working status, experience with economic experiments and the profit in part 1.

At the end of the 5 minutes of chatting in the instant-messaging-program, you need to indicate whether you would prefer to be buyer or seller. If one person in a pair indicates a preference for being in the role of buyer, and the other person indicates a preference for the role of seller, then the roles will be assigned exactly as preferred by both members of the pair. If this is not the case, then roles will be assigned randomly.

Before period 21 and 31 you will again have 5 minutes time to exchange messages with your partner. Roles may not be changed in the course of communication before these periods, however. As soon as the periods start, no further communication is possible.

\section{Interaction of buyers and sellers}

In each period there will be an interaction between a buyer and a seller, in which they decide about buying, or respectively selling, a card. It is very important to note that you will never interact with the partner in your team! This means that if you are a buyer, for example, you will never trade with the seller in your pair, and vice versa.

In each period, it will be randomly determined which buyer will interact with which seller (taking care of the limitation that interaction within pairs is impossible). In each period it is equally likely to interact with any of the participants in the opposite role of yours. Recall that the interaction always takes place with someone from a different pair. 


\section{How to buy a card in each period}

Buyers are in the same situation as all participants were in part 1 of the experiment. In each period you can bid in the role of buyer for a card. The card's nominal value will be determined randomly as in part 1 . To remember: the nominal value may be 90,600 , or 1,200, with equal probability.

In each period, you have to submit a bid as an integer number from 0 to 2,000, including both 0 and 2,000. The card's nominal value will be determined and revealed after you have placed your bid.

As the buyer, you get an initial endowment of $\mathbf{1 0} €$ for part 2, and as seller you get $\mathbf{2} €$. This endowment will be added to the profit in the first period of part 2. However, please note the rules for determining payoffs within pairs at the end of this set of instructions!

\section{Selling a card in each period and profits of the seller}

In the role of seller you are the owner of the card that can be sold in each period and for which the buyer places a bid. You can earn money in the role of seller if you sell the card to the buyer. You will be informed about the card's nominal value (either 90, 600, or 1,200) and the buyer's bid before you decide whether or not to sell your card. If you sell the card, then you earn the buyer's bid minus the card's nominal value. For example, if the card has a nominal value of 600 and the buyer has bid 712, then you earn 112 points if you sell the card. Assume that the card had a nominal value of 600, the buyer bid 457 and you sold it, then you lose 143 points. Whenever you don't sell the card, then you don't earn anything in this period, but you also don't lose anything.

\section{Profits from buying a card}

As in part 1, a buyer gets $150 \%$ of the card's nominal value if the seller sold it to him or her. Once the seller has sold the card, the buyer has to buy it.

An example:

Assume that in the role of buyer you have bid 712 points and that the realized nominal value is 600:

1. If the seller sells the card, then the buyer earns 188 points $(=600 * 1,5-712)$

2. If the seller does not sell the card, then the buyer earns zero.

\section{Feedback}

At the end of each period you will see an "outcome screen" on which you'll see for all previous periods of part 2 the following information: the card's nominal value, the buyer's bid, whether the seller has sold the card, and your profit.

\section{Rules for profits within pairs}

At the end of the experiment, all profits from each period of part 2 will be added up. Then the profits of the buyer and the seller within a pair will be summed and both members of the pair will receive exactly one half of the joint profits from part 2 . This includes also sharing the initial endowments from the beginning of part 2. The exchange rate is again:

$$
\text { 2.5points }=0.01 € \text {. }
$$


Table A.1. Demographic data collected at the end of part 1 of the experiment.

\begin{tabular}{|c|c|}
\hline Variable & Coding \\
\hline Age & $\begin{array}{l}0=18 \text { years or younger; } 1=19 \text { years; } 2=20 \text { years; } 3=21 \text { years; } \\
4=22 \text { years; } 5=23 \text { years; } 6=24 \text { years; } 7=25 \text { years; } 8=26 \text { years or } \\
\text { older. }\end{array}$ \\
\hline Gender & $1=$ female; $0=$ male. \\
\hline Field of study & $\begin{array}{l}\text { 0=economics and business; } 1=\text { medicine; } 2=\text { political science; } \\
\text { 3=psychology; } 4=\text { sociology; } 5=\text { other. }\end{array}$ \\
\hline Population of hometown & $\begin{array}{l}0=\text { under } 5.000 ; 1=5.000 \text { to } 10.000 ; 2=10.000 \text { to } 25.000 ; \\
3=25.000 \text { to } 50.000 ; 4=50.000 \text { to } 100.000 ; 5=100.000 \text { to } 500.000 ; \\
6=\text { more than } 500.000 .\end{array}$ \\
\hline Worl & $\begin{array}{l}0=\text { Full time student; } 1=\text { Full time student plus part time worker; } \\
2=\text { Full time student and full time worker; } 3=\text { Part time student; } \\
4=\text { Part time student and part time worker; } 5=\text { Part time student } \\
\text { and full time worker; } 6=\text { neither student nor worker; } 7=\text { No } \\
\text { student, but part time worker; } 8=\text { No student, but full time worker. }\end{array}$ \\
\hline $\begin{array}{l}\text { Experience } \\
\text { experiments }\end{array}$ & $\begin{array}{l}0=\text { never participated before; } 1=1 \text { to } 3 \text { times participated; } 2=4 \text { to } \\
10 \text { times participated; } 3=11 \text { to } 20 \text { times participated; } 4=\text { more than } \\
20 \text { times participated. }\end{array}$ \\
\hline $\begin{array}{l}\text { Math grade in high- } \\
\text { school leaving exam } \\
\text { ("Matura") }\end{array}$ & $\begin{array}{l}\text { Grades range from } 1 \text { to } 5 \text { (in integers). " } 1 \text { " is the best grade, " } 5 \text { " } \\
\text { the worst. }\end{array}$ \\
\hline $\begin{array}{l}\text { German grade in high- } \\
\text { school leaving exam } \\
\text { ("Matura") }\end{array}$ & $\begin{array}{l}\text { Grades range from } 1 \text { to } 5 \text { (in integers). " } 1 \text { " is the best grade, " } 5 \text { " } \\
\text { the worst. }\end{array}$ \\
\hline
\end{tabular}


University of Innsbruck - Working Papers in Economics and Statistics Recent Papers can be accessed on the following webpage:

http://eeecon.uibk.ac.at/wopec/

2011-14 David J. Cooper, Matthias Sutter: Role selection and team performance

2011-13 Wolfgang Höchtl, Rupert Sausgruber, Jean-Robert Tyran: Inequality aversion and voting on redistribution

2011-12 Thomas Windberger, Achim Zeileis: Structural breaks in inflation dynamics within the European Monetary Union

2011-11 Loukas Balafoutas, Adrian Beck, Rudolf Kerschbamer, Matthias Sutter: What drives taxi drivers? A field experiment on fraud in a market for credence goods

2011-10 Stefan Borsky, Paul A. Raschky: A spatial econometric analysis of compliance with an international environmental agreement on open access resources

2011-09 Edgar C. Merkle, Achim Zeileis: Generalized measurement invariance tests with application to factor analysis

2011-08 Michael Kirchler, Jürgen Huber, Thomas Stöckl: Thar she bursts reducing confusion reduces bubbles modified version forthcoming in American Economic Review

2011-07 Ernst Fehr, Daniela Rützler, Matthias Sutter: The development of egalitarianism, altruism, spite and parochialism in childhood and adolescence

2011-06 Octavio Fernández-Amador, Martin Gächter, Martin Larch, Georg Peter: Monetary policy and its impact on stock market liquidity: Evidence from the euro zone

2011-05 Martin Gächter, Peter Schwazer, Engelbert Theurl: Entry and exit of physicians in a two-tiered public/private health care system

2011-04 Loukas Balafoutas, Rudolf Kerschbamer, Matthias Sutter: Distributional preferences and competitive behavior forthcoming in Journal of Economic Behavior and Organization

2011-03 Francesco Feri, Alessandro Innocenti, Paolo Pin: Psychological pressure in competitive environments: Evidence from a randomized natural experiment: Comment 
2011-02 Christian Kleiber, Achim Zeileis: Reproducible Econometric Simulations

2011-01 Carolin Strobl, Julia Kopf, Achim Zeileis: A new method for detecting differential item functioning in the Rasch model

2010-29 Matthias Sutter, Martin G. Kocher, Daniela Rützler and Stefan T. Trautmann: Impatience and uncertainty: Experimental decisions predict adolescents' field behavior

2010-28 Peter Martinsson, Katarina Nordblom, Daniela Rützler and Matthias Sutter: Social preferences during childhood and the role of gender and age - An experiment in Austria and Sweden Revised version forthcoming in Economics Letters

2010-27 Francesco Feri and Anita Gantner: Baragining or searching for a better price? - An experimental study. Revised version accepted for publication in Games and Economic Behavior

2010-26 Loukas Balafoutas, Martin G. Kocher, Louis Putterman and Matthias Sutter: Equality, equity and incentives: An experiment

2010-25 Jesús Crespo-Cuaresma and Octavio Fernández Amador: Business cycle convergence in EMU: A second look at the second moment

2010-24 Lorenz Goette, David Huffman, Stephan Meier and Matthias Sutter: Group membership, competition and altruistic versus antisocial punishment: Evidence from randomly assigned army groups

2010-23 Martin Gächter and Engelbert Theurl: Health status convergence at the local level: Empirical evidence from Austria (revised Version March 2011)

2010-22 Jesús Crespo-Cuaresma and Octavio Fernández Amador: Buiness cycle convergence in the EMU: A first look at the second moment

2010-21 Octavio Fernández-Amador, Josef Baumgartner and Jesús CrespoCuaresma: Milking the prices: The role of asymmetries in the price transmission mechanism for milk products in Austria

2010-20 Fredrik Carlsson, Haoran He, Peter Martinsson, Ping Qin and Matthias Sutter: Household decision making in rural China: Using experiments to estimate the influences of spouses

2010-19 Wolfgang Brunauer, Stefan Lang and Nikolaus Umlauf: Modeling house prices using multilevel structured additive regression

2010-18 Martin Gächter and Engelbert Theurl: Socioeconomic environment and mortality: A two-level decomposition by sex and cause of death 
2010-17 Boris Maciejovsky, Matthias Sutter, David V. Budescu and Patrick Bernau: Teams make you smarter: Learning and knowledge transfer in auctions and markets by teams and individuals

2010-16 Martin Gächter, Peter Schwazer and Engelbert Theurl: Stronger sex but earlier death: A multi-level socioeconomic analysis of gender differences in mortality in Austria

2010-15 Simon Czermak, Francesco Feri, Daniela Rützler and Matthias Sutter: Strategic sophistication of adolescents - Evidence from experimental normalform games

2010-14 Matthias Sutter and Daniela Rützler: Gender differences in competition emerge early in live

2010-13 Matthias Sutter, Francesco Feri, Martin G. Kocher, Peter Martinsson, Katarina Nordblom and Daniela Rützler: Social preferences in childhood and adolescence - A large-scale experiment

2010-12 Loukas Balafoutas and Matthias Sutter: Gender, competition and the efficiency of policy interventions

2010-11 Alexander Strasak, Nikolaus Umlauf, Ruth Pfeifer and Stefan Lang: Comparing penalized splines and fractional polynomials for flexible modeling of the effects of continuous predictor variables

2010-10 Wolfgang A. Brunauer, Sebastian Keiler and Stefan Lang: Trading strategies and trading profits in experimental asset markets with cumulative information

2010-09 Thomas Stöckl and Michael Kirchler: Trading strategies and trading profits in experimental asset markets with cumulative information

2010-08 Martin G. Kocher, Marc V. Lenz and Matthias Sutter: Psychological pressure in competitive environments: Evidence from a randomized natural experiment: Comment

2010-07 Michael Hanke and Michael Kirchler: Football Championships and Jersey sponsors' stock prices: An empirical investigation

2010-06 Adrian Beck, Rudolf Kerschbamer, Jianying Qiu and Matthias Sutter: Guilt from promise-breaking and trust in markets for expert services Theory and experiment

2010-05 Martin Gächter, David A. Savage and Benno Torgler: Retaining the thin blue line: What shapes workers' intentions not to quit the current work environment 
2010-04 Martin Gächter, David A. Savage and Benno Torgler: The relationship between stress, strain and social capital

2010-03 Paul A. Raschky, Reimund Schwarze, Manijeh Schwindt and Ferdinand Zahn: Uncertainty of governmental relief and the crowding out of insurance

2010-02 Matthias Sutter, Simon Czermak and Francesco Feri: Strategic sophistication of individuals and teams in experimental normal-form games

2010-01 Stefan Lang and Nikolaus Umlauf: Applications of multilevel structured additive regression models to insurance data 


\title{
University of Innsbruck
}

\section{Working Papers in Economics and Statistics}

\section{$2011-14$}

David J. Cooper, Matthias Sutter

Role selection and team performance

\begin{abstract}
Team success relies on assigning team members to the right tasks. We use controlled experiments to study how roles are assigned within teams and how this affects team performance. Subjects play the takeover game in pairs consisting of a buyer and a seller. Understanding optimal play is very demanding for buyers and trivial for sellers. Teams perform better when roles are assigned endogenously or teammates are allowed to chat about their decisions, but the interaction effect between endogenous role assignment and chat unexpectedly worsens team performance. We argue that ego depletion provides a likely explanation for this surprising result.
\end{abstract}

ISSN 1993-4378 (Print)

ISSN 1993-6885 (Online) 